\title{
Los espacios como dispositivo de la construcción de prácticas corporales y coreográficas contemporáneas. A propósito del contact improvisation en el contexto español
}

\author{
The Spaces as a Device for the Construction of \\ Contemporary Corporal and Choreographic Practices. \\ About Contact Improvisation in the Spanish Context
}

\author{
María Paz Brozas Polo ${ }^{1}$ \\ Universidad de León
}

\section{RESUMEN}

En este artículo se categorizan y analizan los lugares donde se baila contact improvisation (CI) en el contexto español entre 2010 y 2015. Partiendo de la idea de que el espacio no solo es construido, sino que a su vez define cuerpos e ideologías en concurrencia con distintas prácticas, se identifican distintas direcciones, confluencias o tensiones que se establecen entre las técnicas corporales, artísticas, educativas y terapéuticas junto a las que la danza CI radica. Tanto el análisis de contenido como el trabajo de campo indican una expansión en el número y variedad de los lugares para la práctica de CI en España; destaca, al respecto, el incremento de espacios rurales residenciales junto a un conjunto amplio de espacios urbanos de danza, interdisciplinares y polivalentes. Estas tendencias en el uso de los espacios de CI dan cuenta de su (di)solución actual y también de la existencia de un espectro de tendencias coreográficas y de movimientos sociales con los que comparte principios estéticos, éticos o pedagógicos y algunas fórmulas de gestión colectiva.

Palabras clave: Danza; Espacios; Técnicas corporales; Contact improvisation.

\section{SUMMARY}

This article categorizes and analyzes the places where contact improvisation (CI) is danced in Spain between the years 2010 and 2015. Starting from the idea that space is not only constructed, but in turn defines bodies and ideologies in concurrence with different practices, we identify some directions, confluences or tensions that are established between the corporal, artistic, educational and therapeutics techniques to which the CI dance is rooted. Both, content analysis and fieldwork indicate an expansion in the number and category of places for the practice of CI in Spain; we highlight, in this regard, the increase of residential rural spaces along with a wide range of urban spaces of dance, interdisciplinary and multipurpose. These trends in the use of various spaces for CI inform about the definition and about the development of a broad spectrum of choreographic tendencies and social movements. CI shares aesthetic, ethical or educational principles, including collective management.

Key words: Dance; Spaces; Body Techniques; Contact Improvisation.

\footnotetext{
${ }^{1}$ Correo electrónico: mpbrop@unileon.es. ORCID iD: http://orcid.org/0000-0003-0117-3117.
} 


\section{INTRODUCCIÓN}

El espacio se comprende, se construye y delimita a través de lo que hacen los cuerpos en él; pero a la vez, en tanto que sitio o lugar, constituye un elemento fundamental para la comprensión de las prácticas que contiene (Milstein y Mendes 1999). A este respecto, Michel de Certeau (2000: 108) propone analizar las prácticas "microbianas, singulares y plurales" del sistema urbanístico y ofrece una definición del espacio en tanto que es habitado. Para él, a diferencia del lugar, que lo concibe como mera configuración de posiciones, el espacio está animado por el conjunto de movimientos que en él se despliegan; se define como un lugar habitado por el cuerpo y sus acciones, como un lugar practicado (Certeau 2000: 129). Del mismo modo, para David Le Breton (1991) el espacio se constituye como el principal referente de la dimensión social del cuerpo y de los aprendizajes corporales.

Con este planteamiento preliminar, y también de acuerdo con la teoría social, entendemos que el espacio no deja de ser un gran operador cultural —no sólo escenográfico- y que las prácticas del espacio tejen las condiciones determinantes de la vida social alrededor del mismo. Dentro del universo de las prácticas o técnicas corporales, en tanto que formas culturales —en la acepción de Marcel Mauss (1979)—, en este artículo nos ocupamos de aquellas que se generan en el ámbito artístico y, sobre todo, en la danza contact improvisation (CI); nos preguntamos particularmente por el modo en que esta danza se relaciona con otras prácticas o actividades físicas (artísticas, creativas, educativas, domésticas, recreativas o terapéuticas) según la tipología espacial en la que se incardinan.

Los ejes conceptuales de este estudio son el espacio, las prácticas corporales que lo habitan y la (in)definición de la danza (CI) en el contexto español actual; en torno a ellos tratamos de aproximarnos a esta práctica coreográfica de fuertes y complejas connotaciones de crítica social (Novack 1990) cuya impronta cultural y artística posmoderna, de origen norteamericano, se encuentra presente en el proceso de reconfiguración de los nuevos cuerpos, de acuerdo con los tiempos y los espacios culturales por los que transita.

Como punto de partida constatamos las problemáticas que, con respecto al uso de los espacios, generan las fuerzas opuestas entre lo concebido y lo practicado de acuerdo con la terminología de André Lefebvre (2013 [1974]). Aquí conjeturamos que el espacio, como elemento activo en la construcción de la propia danza, se impone como un indicador privilegiado de las variopintas formas de concebir y experimentar las prácticas gracias a sus múltiples y sus, a veces, contradictorias dimensiones: física/ social, real/ideal, escénica/comunicativa, etc. Mientras que el espacio se privatiza por la actividad económica y se fragmenta en la actividad científico-técnica, se produce una nueva relación del cuerpo y de la sociedad que tiende a la gestión colectiva de las escaseces y, por tanto, de la insuficiencia de espacio (Lefebvre 2013 [1974]: 225). En este sentido, parafraseando a Foucault (2009), planteamos que el espacio aún no está desacralizado; que es posible que aún no hayamos accedido a una secularización práctica del espacio tal que permita superar las oposiciones entre el espacio cultural y el espacio útil o entre el espacio de ocio y el espacio de trabajo.

A partir de dicha constatación, nos preguntamos cómo la danza CI parece atreverse a producirse en emplazamientos con y sin lugar real, en utopías y, a veces, en 
beterotopías, es decir, en espacios distintos, en cualquier lugar dispuesto a acoger la experiencia coreográfica. En todo caso, notando que a lo largo del siglo XX se fue consumando una progresiva especialización de los espacios y una paulatina diferenciación entre lo público y lo privado (Prost 1992), planteamos que la danza posmoderna, de la que forma parte del CI, consiguió diluir estas diferenciaciones —al menos desde los años 60- a través de un uso más abierto y democrático de lugares y prácticas.

La conceptualización del CI como práctica de la posmodernidad obedece a la confluencia de los patrones estéticos y pedagógicos que la caracterizan con los presupuestos de este movimiento. No es solo una cuestión de coincidencia histórica sino también de referencias artísticas —el posmodernismo- en las cuales se inspira; particularmente, en la producción poética y la práctica interdisciplinar del Black Mountain College que eclosiona a mediados del siglo XX en Estados Unidos (Ballesteros 2000 [1989]) y tiene una rápida difusión internacional.

A este respecto, cabe precisar que el CI, es una forma de danza contemporánea surgida en los Estados Unidos en los años setenta. De acuerdo con los postulados del arte posmoderno que le fueron dando forma, se trata de una propuesta coreográfica que tiende a simplificar las condiciones del espacio escénico y que utiliza y propicia una definición de escenario muy alejado del teatro a la italiana; al contrario, está en su esencia la infiltración en cualquier otro lugar ya sea de carácter artístico (como los museos), o de cualquier otra naturaleza como la calle, los parques o las plazas (Banes 2002), edificios públicos, etc. Al tratarse de una práctica esencialmente colectiva, desde sus inicios ha suscitado la preocupación de los bailarines por encontrar a otros bailarines con quienes compartir y aprender; asimismo, como un espacio, cualquier espacio, a condición de que permitiera esta práctica y su peculiar proceso de enseñanza-aprendizaje (Novack 1990).

Victoria Pérez Royo (2008), alguno de cuyos trabajos versa sobre los diversos modos en que la danza contemporánea se ha desarrollado en la calle desde los años sesenta, ha documentado la aparición de nuevos espacios — públicos y privados, urbanos y en entornos naturales- donde se dan cita este tipo de propuestas artísticas; presta especial atención a los espacios como lugares escénicos, pero también da cuenta de la transformación de los procesos de creación de la danza con el surgimiento de las nuevas estéticas de la espontaneidad, la exploración, la improvisación y la adaptación (Pérez Royo 2008: 14). En el CI, como parte de esta tendencia, el proceso de la improvisación en la formación, en el proceso creativo y en la puesta en escena, constituye el eje definidor de la danza, tal como señala Gil (2001), y precisamente, por ello pensamos que exige una atención particular al entorno.

Con todo, se puede decir que el desarrollo pedagógico y social del CI ha ido de la mano de un uso cada vez más amplio y diverso de espacios. En el contexto español —al que se ciñe este estudio_-, la expansión del CI responde además a intereses formativos en el ámbito estético y creativo y, asimismo, a motivaciones relacionadas con la búsqueda de experiencias de un sector de la población donde predominan bailarines con múltiples y diversas expectativas (Brozas 2014) pero donde se dan cita los más diversos perfiles e intereses. Más concretamente, en la década de los 90, en España, "se comienzan a establecer las condiciones para la definición del CI como danza social y como técnica corporal interdisciplinar, pues se facilita el acceso de participantes heterogéneos desde espacios y perspectivas no solo coreográficos" (Brozas 2016). 
Retomando la idea de que el espacio se construye en la práctica y que, a su vez, este define los cuerpos y las ideologías en la confluencia de todo cuanto tiene lugar, habita o ha habitado dicho espacio, en este análisis indagamos en las asociaciones que se establecen entre las distintas técnicas corporales con las que el CI cohabita simbióticamente y en el modo en que dicha cohabitación determina su propia identidad como práctica posmoderna. Del estudio de los espacios de CI pretendemos obtener información que contribuya a definir esta técnica de danza en el contexto actual y que, al mismo tiempo, nos permita comprender el tejido cultural de las prácticas corporales contemporáneas.

\section{MÉTODO, MATERIALES E INVENTARIO DE ESPACIOS REGISTRADOS}

Este artículo forma parte de una serie de estudios que constituye una aproximación histórica y pedagógica a la definición del CI. La investigación surge de la preocupación particular por identificar el proceso de configuración y desarrollo en el contexto español. Dicho contexto, el más próximo a la autora, se analiza no obstante sin perder de vista la referencia de otros contextos, como el americano, donde surge el CI, o el de otros países europeos con los que sin duda mantiene estrechos nexos, algunos de los cuales han sido objeto de exploración por la autora como bailarina, como estudiante y como docente desde 1997 hasta la actualidad (Véase Anexo 1).

En publicaciones previas se ha puesto de manifiesto el protagonismo del espacio en la evolución de esta técnica «en la medida en que consigue albergar de forma más o menos regular o continuada los procesos de formación y experimentación específicos de la danza" (Brozas y García 2014b: 177). Asimismo, con relación al tipo de lugares que acogen las sesiones de improvisación denominadas jams, se ha constatado el uso tanto de espacios públicos como privados, la emergencia de las asociaciones y el uso no solo de espacios artísticos sino de espacios sociales o culturales, así como de espacios abiertos tales como calles y plazas (Brozas 2014: 113) registradas entre 2010 y 2013 (Tabla 1).

En el trabajo que nos ocupa, la teoría social permite poner en diálogo, a través del análisis de contenido, los estudios sobre arte y danza con otras disciplinas humanísticas. Se han revisado, además, las publicaciones españolas o sobre el contexto español que tratan de CI (Brozas 2000; Brozas, Zabaleta y Morales 2001; Padilla y Hermoso 2002; Castañer y Torrents 2008; Zurdo 2005 y 2008; Becker 2009; Castañer, Torrents, Disunova y Anguera 2009; Padilla y Zurdo 2009; Melguizo 2010; Torrents, Castañer, Dinunova y Anguera 2010; Boullosa y Montes 2011; Torrents, Hristovski y Balagué i Senre 2013; Maldonado 2013; Brozas 2013 y 2014; Brozas y García $2014 a$ y b; Gimeno 2014; Brugarolas 2015; Brozas 2016).

Por otra parte, la autora cuenta con una particular implicación en la organización de cursos y jams desde 2007, en el marco del Aula de Artes del Cuerpo de la Universidad de León (<http://blogs.unileon.es/danzaule/>). Asimismo, cabe considerar su estrecha relación con los colectivos de profesores y organizadores de CI en España $<$ http://www.contactimprov.es/maestros_y_organizadores/>) y en otros países (http:// www.ecite.org/). 


\begin{tabular}{|c|c|c|}
\hline $\begin{array}{c}\text { ESPACIOS DE } \\
\text { JAMS }\end{array}$ & ESPACIOS PRIVADOS & ESPACIOS PÚBLICOS \\
\hline $\begin{array}{l}\text { Centros de } \\
\text { danza y artes } \\
\text { del } \\
\text { movimiento }\end{array}$ & $\begin{array}{l}\text { Barcelona: Área, espacio de danza y creación/ } \\
\text { Arlequi. Centro de Danza y Teatro/La Caldera, } \\
\text { centro de creación de danza y artes escénicas/El } \\
\text { Graner, centro de creación en el lenguaje del } \\
\text { cuerpo y del movimiento/Tragandansa. } \\
\text { Educación y creación en movimiento/La Ravalera: } \\
\text { tango y movimiento. } \\
\text { Valencia: El Botanic Spai de Dansa/Eva Bertomue } \\
\text { Centro de Danza; Sala Saltamontes. Espacio } \\
\text { Multidisciplinar de artes del movimiento } \\
\text { Sevilla: Sala Danza Mobile }\end{array}$ & $\begin{array}{l}\text { Girona: Escuela Municipal de } \\
\text { Danza de Celrá. } \\
\text { Palma Mallorca: Conservatorio de } \\
\text { música y danza de Palma. } \\
\text { San Sebastián: Escuela Municipal } \\
\text { de Música y Danza. }\end{array}$ \\
\hline $\begin{array}{l}\text { Espacios de } \\
\text { Artes } \\
\text { Escénicas }\end{array}$ & $\begin{array}{l}\text { Barcelona: La Banyera. Danza, Teatro, Música. } \\
\text { Granada: EnClave. Espacio de artes escénicas y } \\
\text { técnicas corporales/ La bombonera. Espacio de } \\
\text { teatro, danza y circo/ La petite artes escénicas. } \\
\text { Madrid: Espacio3. Teatro, cine, danza y desarrollo } \\
\text { personal/ Espacio Temporal. Artes escénicas. } \\
\text { Murcia: La Chimenea Escénica. Espacio } \\
\text { autogestionado para la creación de las artes } \\
\text { escénicas. }\end{array}$ & $\begin{array}{l}\text { Murcia: Centro Párraga; Espacio } \\
\text { de investigación y desarrollo para } \\
\text { las artes escénicas. } \\
\text { Palma de Mallorca: Quarter } \\
\text { d'Intendencia del CRCC Centre de } \\
\text { Recursos de Creació } \\
\text { Contemporánia. } \\
\text { Santa M M del Camí (Mallorca): } \\
\text { Factoría de les Arts. Escuela de } \\
\text { artes escénicas. }\end{array}$ \\
\hline $\begin{array}{l}\text { Espacios de } \\
\text { Arte (artes } \\
\text { plásticas) y } \\
\text { asociaciones } \\
\text { culturales }\end{array}$ & $\begin{array}{l}\text { Barcelona: Sala de Arte/Anaglifos; Espai Barabal. } \\
\text { Centro de formación y creación artística. } \\
\text { Gijón: El Hervidero. Galería Espacio Líquido/ La } \\
\text { Cámara. Asociación cultural, espacio de teatro y } \\
\text { danza. } \\
\text { La Coruña: Manicómicos, asociación cultural. } \\
\text { Madrid: Aula 11/ Espacio en Blanco/ La Nave. } \\
\text { Centro de creación interdisciplinar. } \\
\text { Murcia: El Quirófano. Espacio Cultural Indep. } \\
\text { Navarra: Sonríe que no es poco. Asociación } \\
\text { Cultural dedicada a la danza y a la música. } \\
\text { Salamanca: Espacio de arte experimental El Gallo. } \\
\text { Zaragoza: Centro Musical y Artístico Las Armas. }\end{array}$ & $\begin{array}{l}\text { San Sebastián: Danzagunea- } \\
\text { Arteleku Centro de arte y cultura } \\
\text { contemporáneo. Dirección de } \\
\text { Cultura de la Diputación Foral de } \\
\text { Guipuzkoa/ La Casa del Guardia. } \\
\text { Espacio de Encuentro y } \\
\text { creatividad. } \\
\text { León: MUSAC de Castilla y León. } \\
\text { Murcia: Foro Artístico. }\end{array}$ \\
\hline $\begin{array}{l}\text { Técnicas } \\
\text { corporales }\end{array}$ & $\begin{array}{l}\text { Barcelona: YogaBindu } \\
\text { Ciutadella de Menorca: Ananda. Centro de Yoga. } \\
\text { Madrid: La Puerta Roja. Pilates \& Danza }\end{array}$ & $\begin{array}{l}\text { Ibiza: La Nave. Centro de } \\
\text { Actividades Artísticas, de } \\
\text { conciencia y Vida. }\end{array}$ \\
\hline $\begin{array}{l}\text { Instituciones } \\
\text { educativas }\end{array}$ & $\begin{array}{l}\text { Murcia: Colegio Concertado } \\
\text { Leonardo Da Vinci. }\end{array}$ & $\begin{array}{l}\text { Badajoz: IES Castelar. } \\
\text { Sevilla (Carmona): IES Manuel } \\
\text { Losada Villasante. } \\
\text { León: Universidad. }\end{array}$ \\
\hline $\begin{array}{c}\text { Espacios } \\
\text { deportivos }\end{array}$ & $\begin{array}{l}\text { Zaragoza: Dojo-Zaragoza. Asociación Deportiva de } \\
\text { Artes Marciales y Deportes de Contacto. }\end{array}$ & $\begin{array}{l}\text { CDM Palafox. Centro deportivo } \\
\text { Municipal de Zaragoza }\end{array}$ \\
\hline $\begin{array}{l}\text { Espacios } \\
\text { socio- } \\
\text { culturales } \\
\text { polivalentes }\end{array}$ & $\begin{array}{l}\text { Badajoz: Círculo Pacense. Sociedad cultural. } \\
\text { Madrid: La Tabacalera. Centro Social } \\
\text { Autogestionado. }\end{array}$ & $\begin{array}{l}\text { Barcelona: Casal Pou de la } \\
\text { Figuera/ Centre Civic Barceloneta } \\
\text { Centre Civid les Cort/ Sala Textil } \\
\text { Rase del Ayto de Cardedeu/ PIC } \\
\text { Centro Social de Can Masdeu/ } \\
\text { Casal AVVE Escodines de } \\
\text { Manresa }\end{array}$ \\
\hline Otros & $\begin{array}{l}\text { La Coruña: Hotel Sada Marina. } \\
\text { Zaragoza: Pantera Rossa. Centro social librería. } \\
\text { Málaga: Recrea. Cooperativa de Ocio Educativo. }\end{array}$ & $\begin{array}{l}\text { Barcelona: Plaza Cataluña. } \\
\text { Burgos: Parque de la Isla. } \\
\text { Palma de Mallorca: Plaza Islandia. }\end{array}$ \\
\hline
\end{tabular}

TABla 1.-Tipología de los espacios de práctica de jams de CI en España 2010-2013. 


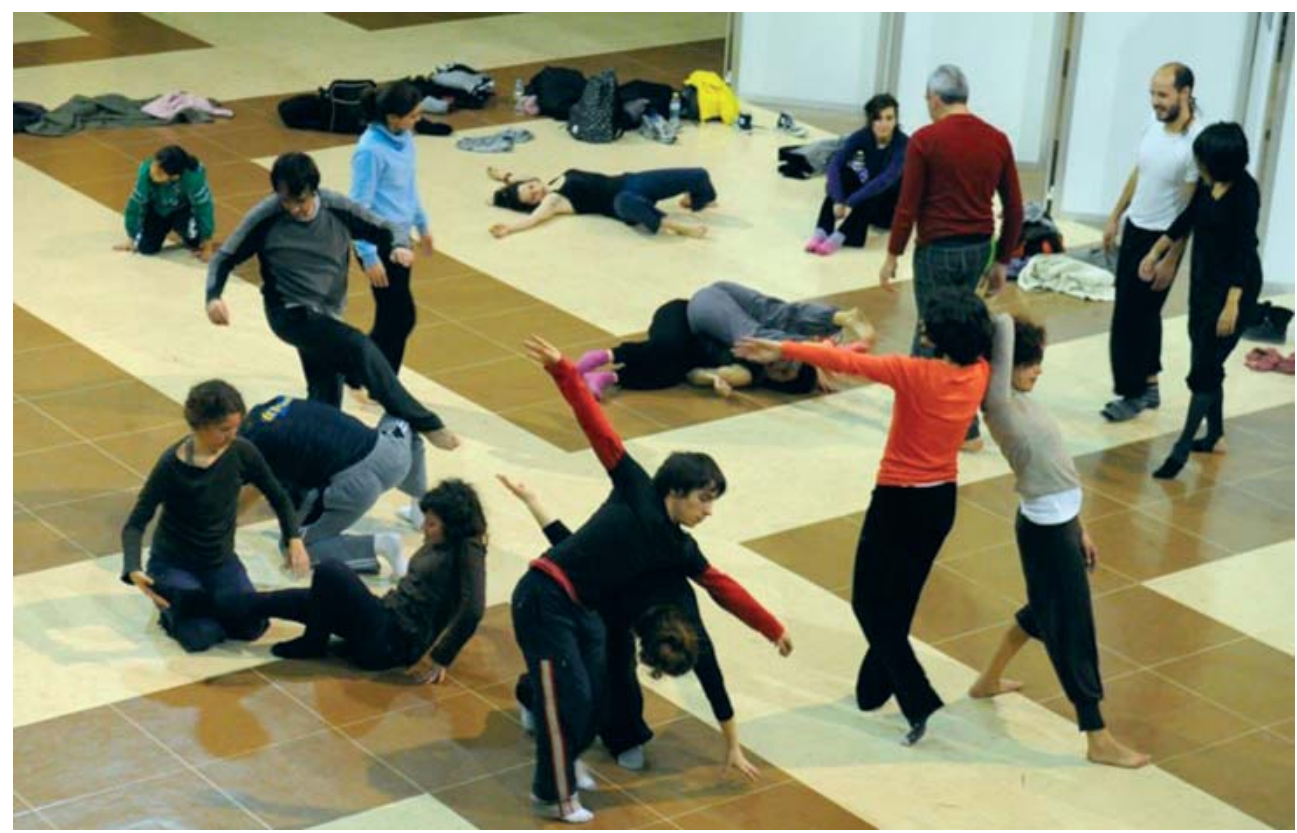

IMAGEN 1.-Jam en el Hall de la Facultad de Filosofía ULE. Foto Julia. G. Liébana.

El desarrollo de la investigación se ha llevado a cabo mediante inmersión en la práctica objeto de estudio con énfasis en los procedimientos de observación participante, a través de cuadernos de campo, siendo el límite temporal 2015. Como parte del método etnográfico, para este estudio se ha procedido a una recogida de datos a través de un cuestionario junto a varias formas de comunicación personal —entrevista en directo, telefónica y a través del correo electrónico-; se ha utilizado, además, una lista de uso interno elaborada en el primer Encuentro de Maestros y Organizadores de CI en España (EMOCIE) que se actualiza cada dos años desde $2010^{2}$. Finalmente, se ha completado la información con la consulta de los grupos y páginas web vigentes de CI en España (Tabla 2). Para el registro de los lugares de práctica han colaborado 42 personas informantes, todas ellas advertidas del objetivo del estudio y de su posible publicación.

El cuestionario referido constaba de cuatro preguntas abiertas sobre la actividad específica de CI del encuestado, su localización, así como sobre los espacios utilizados y conocidos en su entorno. Se entregó el documento en papel a los treinta asistentes al EMOCIE celebrado en Caudiel (Alicante), del 5 al 8 de diciembre de 2014,

${ }^{2}$ Agradecimientos. A todas las personas involucradas en la práctica del CI en distintos lugares de la geografía española que han sido consultadas para este estudio y, en particular, a las integradas en los colectivos organizadores de los encuentros EMOCIE que se celebran bienalmente desde 2010 y que han permitido compartir, además de la danza, el conocimiento y la experiencia de distintas localidades y comunidades en torno al CI. 


\section{BLOGS Y WEBS DE CONTACT IMPROVISATION}

Asturias Contact Festival http://www.asturiascontactfestival.com/

CI Summer Meting Barcelona https://cimeeting.wordpress.com/

CIM Contact Improvisación Málaga http://contactimpromalaga.blogspot.com.es/

Contact-teu http://www.contact-teu.com/

Contact Improvisation España http://www.contactimprov.es/

Contact Lleida www.contactlleida.blogspot.com

Contactmadrid-jams https://lists.ourproject.org/cgi-bin/mailman/listinfo/contactmadrid-jams

EHKIE Asociación de CI del País Vasco https://ehkiekontakt.wordpress.com/

Danza Contact en Sevilla http://contactimprovisation.es

Desert Contact Almeria https://desertcontactalmeria.wordpress.com/

Fuerteventura Contact Festival http://canarian.contactfestival.info/

Ibiza Contact Festival http://ibizacontactfestival.com/es/inicio/

MOU-LO Asociación de Contact Improvisación de Lleida

http://lleidacontact.blogspot.com.es/

Nexus: grupo de Danza Contact-Impro Sevilla http://contactimprovisation.es/

GRUPOS DE FACEBOOK DE CONTACT IMPROVISATION

\section{ASTURIAS CONTACT IMPRO}

https://www.facebook.com/groups/155762717942078/members/

CLASES DE CONTACT DANCE (en Valencia)

https://www.facebook.com/events/384136858428381/

Contact Improvisation Almeria

https://www.facebook.com/groups/contact.improvisation.almeria/

CONTACT IMPROVISACIÓN CÓRDOBA

https://www.facebook.com/groups/1386135668299962/

CONTACT IMPROVISATION GALICIA

https://www.facebook.com/groups/840384362661206/?ref=ts\&fref=ts

Contact Improvisación León https://www.facebook.com/groups/218979054905591/

https://www.facebook.com/groups/contactimpromadrid/

Contact Improvisación Málaga www.contactimpromalaga.blogspot.com

Contact Improvisación Mallorca https://www.facebook.com/groups/224298307633706/?fref=ts

Contact Impro Salamanca https://www.facebook.com/groups/1451918745033360/?fref=ts

Contact Improvisation Sevilla https://www.facebook.com/contactimprovisationsevilla/

Contact Impro Sierra de Gata

https://www.facebook.com/pages/Contact-Impro-Sierra-de-Gata/594991013926027?fref=ts

Contactuco (Cantabria)

https://www.facebook.com/groups/216544971865266/permalink/216558608530569/

DANZA CONTACT EN FAMILIA https://www.facebook.com/groups/630950657004808/?fref=ts

EHKIE Ehkie CI Euskal Herria

https://www.facebook.com/profile.php?id=100008331576166\&fref $=$ ts

EMOCIE (Encuentro de Maestros y Organizadores de CI en España)

https://www.facebook.com/groups/294868587405/?fref=ts

Kontact Donostia Contact San Sebastián

https://www.facebook.com/groups/donostiakontakt/?fref=ts

Jam Contac Impro Bilbao https://www.facebook.com/events/1576619502624133/

Jam Contact Barcelona https://www.facebook.com/groups/jamcontactbarcelona/

Jam Contact Mataró https://www.facebook.com/groups/226180780768727/

TABLA 2.-Sitios on line específicos de Contact Improvisation en España (Activos en 2015). 
de los cuales se completaron diecisiete. El 20 de enero 2015 se envió de nuevo el cuestionario por correo electrónico a un total de 162 direcciones de docentes, coreógrafos, estudiosos o gestores de CI en España. A partir de este envío se estableció correspondencia con otras dieciocho personas implicadas a través de correo electrónico. El 18 de mayo de 2015 se envió todo el grupo un listado provisional de Espacios de CI en España, para su cotejo, tras el cual se recibieron siete nuevos correos indicando alguna corrección, consideración o dato adicional. El 9 de julio de 2015 se hicieron públicos los listados de sitios específicos registrados hasta 2015 mediante envío al grupo de EMOCIE que trasladó la información al apartado de documentación (<http://www.contactimprov.es/category/docu/>) para uso público (véase Anexo 2).

Tras el todo el proceso se concluyó la existencia de 103 espacios dedicados a la práctica de CI en 2014 y 2015. Estos espacios se han clasificado en diez categorías, cuatro relativas a distintas artes, cuatro referidas a espacios sociales, educativos, terapéuticos o recreativos y otras dos relativas a lugares propios de técnicas de conciencia corporal o de mantenimiento físico (Tabla 3). Estos datos ya nos revelan un cierto equilibrio cuantitativo entre espacios específicos de danza y otros espacios artísticos de artes escénicas (teatro y/o circo) o arte en general; asimismo, entre los espacios propiamente artísticos y otros espacios sociales, educativos o específicos de técnicas corporales. En la tabla se pone de manifiesto la diversidad de los marcos espaciales donde se practica CI, la cual se podría asociar con los distintos enfoques u orientaciones de esta técnica de danza contemporánea.

De todas las comunidades autónomas del Estado español, excepto de La Rioja, se han encontrado uno o más espacios de práctica (Tabla 4). Los distintos indicadores señalan la diversidad de dichos espacios, pero no se relacionan directamente con la cantidad de práctica o actividad de CI. El despunte de Andalucía se ha de interpretar considerando el uso reciente de múltiples espacios en la naturaleza, que supera el número de espacios de comunidades como Cataluña o Madrid que fueron las comunidades pioneras en esta práctica (Brozas y García 2014b).

Una dificultad, que al mismo puede ser tomada como una evidencia del estudio, fue el carácter efímero de algunos lugares como espacios de práctica de CI; observamos, además, en algunos casos, cierta alternancia entre la ocupación y la desocupación en el periodo analizado entre 2010 a 2015. La propia dinámica de las prácticas emergentes, que responden a la expansión de los valores de la posmodernidad y/o a la ley de mercado, confluye con un periodo de crisis económica en donde los centros de gestión privada subsisten con dificultad y las instituciones, en algunos casos, han disminuido los apoyos o modificado las condiciones de la cesión de espacios a los particulares o a asociaciones (T. Martínez, comunicación personal, 14 febrero 2013; M. Gonzo, comunicación personal, 18 abril 2015; V. Maldonado, comunicación personal, 14 noviembre 2016).

A estas circunstancias, se añade el hecho de que, entre las fórmulas didácticas propias del CI en el contexto, algunas se caracterizan por ser actividades intensivas no regulares que pueden llegar a ser eventuales o distantes en el tiempo. Un ejemplo es el EMOCIE que se realiza desde 2010 de forma bienal en distintas sedes (Arlequi en Bañolas, El Cielo de la Vera en la provincia de Cáceres, Asociación Sirio en Caudiel, Castellón); otro ejemplo es el Encuentro Vasco de CI o Topaketa (<https://ehkiekontakt. wordpress.com/topaketa/>), un encuentro anual que ha optado por utilizar una sede rural 


\begin{tabular}{|c|c|c|}
\hline Contextos & Categorías & Nombres \\
\hline \multirow{4}{*}{$\begin{array}{l}\text { Danza, artes } \\
\text { escénicas y } \\
\text { creación } \\
\quad(49)\end{array}$} & $\begin{array}{c}\text { Danza } \\
(21)\end{array}$ & $\begin{array}{l}\text { Bacantoh, BambúDanza, Belin Cabrillo, Bellydance, Carmen Senra, } \\
\text { Centro Hélade, Conservatorio de Málaga, Conservatorios Mariemma y } \\
\text { María de Avila, EBCD Eva Bertomeu, Escuela Municipal de Danza de } \\
\text { Celrá, EnClave, Paso a Paso, ENEstudio, Espacio en Blanco, Estudio } \\
\text { 12, Es local, Karen Taft, La Casa Amarilla, Muelle3, Tragantdansa, } \\
\text { Zinzaló, }\end{array}$ \\
\hline & $\begin{array}{l}\text { Teatro } \\
(8)\end{array}$ & $\begin{array}{l}\text { Casa del Agua, Escuela de Arte Dramático de Málaga y Palma } \\
\text { Mallorca, Estudio3, Escuela Municipal de Música y Danza San } \\
\text { Sebastián, Espacio Espiral, La Nómada, Teatre Municipal de } \\
\text { l'Escorxador, }\end{array}$ \\
\hline & $\begin{array}{l}\text { Circo } \\
(6)\end{array}$ & $\begin{array}{l}\text { Almacabra, Circo bajo el Tejado, La Pequeña Nave, La Chimenea } \\
\text { Escénica, Karola Zirko, Sala CAU, }\end{array}$ \\
\hline & $\begin{array}{l}\text { Arte } \\
\text { (14) }\end{array}$ & $\begin{array}{l}\text { Centro Párraga, Cuartel de Artillería, Danzagunea, El Arsenal, El } \\
\text { Quirófano, Espacio ZM, Espai Orfeó, Jazar, La Cámara, La fábrica de } \\
\text { Chocolate, La Térmica, MUSAC, Puertas de Castilla, Zaldi Urdina }\end{array}$ \\
\hline \multirow{2}{*}{$\begin{array}{l}\text { Encuentro } \\
\text { social, ocio y } \\
\text { bienestar } \\
\quad(28)\end{array}$} & $\begin{array}{l}\text { Social } \\
(12)\end{array}$ & $\begin{array}{l}\text { Aurea Social, La Fustería, Centro Cívico La Barceloneta, Centro Juvenil } \\
\text { La Nave, D-Espacio Partycipa, Espacio Vías, La Casa Invisible, La } \\
\text { Variable, La Tabacalera, Palau Alos, Parque Ciutadella, Parque Retiro, }\end{array}$ \\
\hline & $\begin{array}{l}\text { Naturaleza o } \\
\text { espacio rural } \\
\quad(16)\end{array}$ & $\begin{array}{l}\text { Albergue de Viznar, Arlequi, Baile en el Aire, Casa Sorábile, Cortijo El } \\
\text { Salvador, Cortijo Los Baños Al-hamam, Dolzamar, La Luz, La Casa del } \\
\text { Búho, La Casona del Uno, La Zarza Dojo, La Semilla Bolonia, Re- } \\
\text { Colectivo, Campamento Cala Jondal, Espacios Ayuntamiento La Oliva, } \\
\text { Santa María de Miraflores, }\end{array}$ \\
\hline \multirow{2}{*}{$\begin{array}{l}\text { Educación y } \\
\text { terapia } \\
\text { (16) }\end{array}$} & $\begin{array}{l}\text { Educación } \\
\quad(8)\end{array}$ & $\begin{array}{l}\text { Aula de Danza UCO, Aula Artes del Cuerpo ULE, Colegio Atakondoa, } \\
\text { Colegio Dolors Granells, IES Castelar, IES de Astorga, IES Los Salados, } \\
\text { Xantala Escuela Libre, }\end{array}$ \\
\hline & $\begin{array}{l}\text { Terapia } \\
(8)\end{array}$ & $\begin{array}{l}\text { Centro Baobab, La Metáfora, Centro Alma, Terapia Humanista, Entre } \\
\text { Arrels, Arteterapia Hephaisto, Asha-kiran, Hermes Terapia Integral, }\end{array}$ \\
\hline \multirow[b]{2}{*}{$\begin{array}{l}\text { Técnicas } \\
\text { corporales } \\
\quad(11)\end{array}$} & Yoga (4) & 3Armonías, Date un respiro, El UP, Happy Yoga, La Savia \\
\hline & $\begin{array}{l}\text { Gimnasios } \\
\text { (6) }\end{array}$ & $\begin{array}{l}\text { La Puerta Roja Pilates \& Danza, Polideportivo Eduardo La Torre, } \\
\text { Polideportivo El Cabanyal, Polideportivo de Llanes, Taio Dojo, } \\
\text { Tenshikan Dojo, }\end{array}$ \\
\hline
\end{tabular}

Tabla 3.-Tipología de espacios de danza CI en España (2014-2015): contextos y categorías.

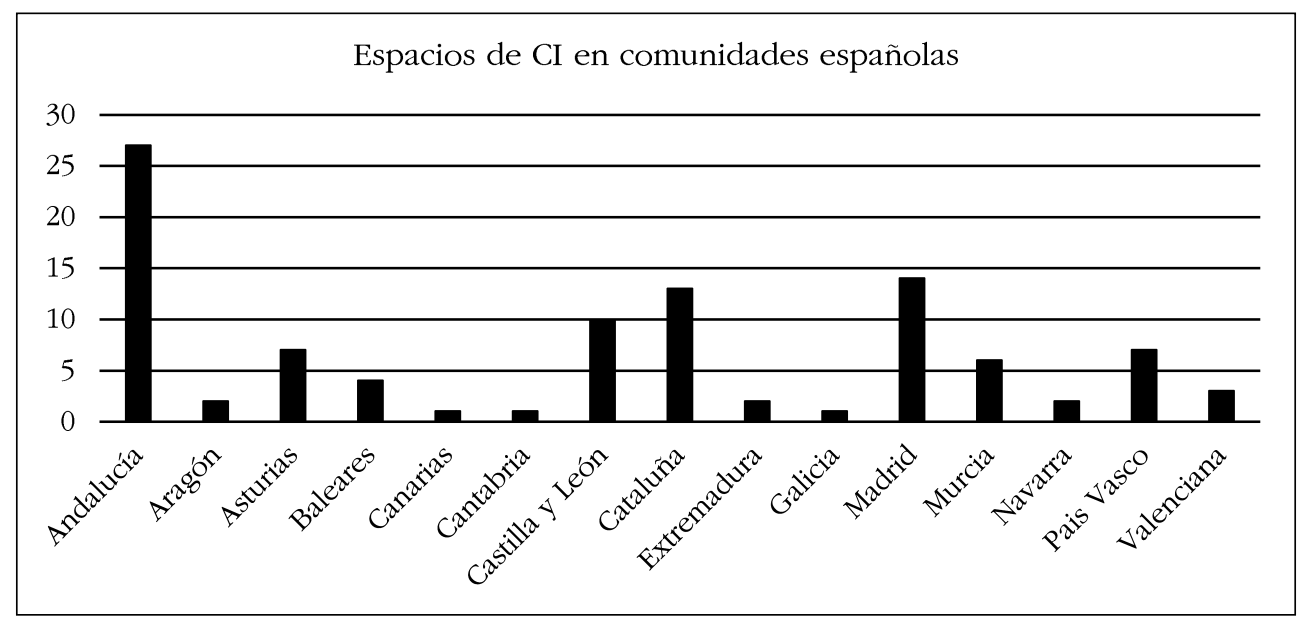

TABla 4.-Espacios de CI en distintas comunidades en 2014-2015. 
distinta cada año. Asimismo, en ocasiones se conciertan espacios para un uso breve y ocasional como puede ser, por ejemplo, el ciclo de jams itinerantes como el organizado en 2015 por la asociación EnClave en Granada (<http://enclavegranada.wixsite.com/ enclave/jam>).

Al intentar categorizar los espacios respecto de las actividades de CI se revelaron las múltiples variantes terminológicas de estas, muchas de las cuales se presentan combinadas entre sí: clases, cursos, intensivos, jams, festivales, laboratorios, encuentros, ensayos, presentaciones, performances, underscores, training, etc. Se pone de manifiesto así la variedad de aproximaciones y metodologías pedagógicas de la danza CI: entre ellos destaca el uso del término Encuentros, ya señalado anteriormente, que acentúa el carácter social de las actividades. Fue utilizado inicialmente por el colectivo de danza Siamb para referirse a los intensivos anuales que fueron evolucionando desde 2001 a 2016. Dicho colectivo incluía, como ocurre en los festivales, otro tipo de actividades, además de las clases, siendo las más frecuentes las jams. Actualmente, se aplica también a las fórmulas más recientes como la Danza Contact en Familia, una práctica en desarrollo dirigida a la inclusión de niños y niñas de edades tempranas que bailan junto a sus progenitores y otros adultos.

En concordancia con la diversidad de prácticas y tendencias corporales contemporáneas, no solamente artísticas, se han seleccionado algunas tipologías espaciales que asocian la técnica objeto de estudio con otras actividades, y que ponen de relieve, asimismo, principios y paradigmas sociales vigentes.

\section{ESPACIOS RURALES Y/O NATURALES: ECOTURISMO Y ECOSOMÁTICA}

Entre todos los lugares registrados destaca el grupo de los situados en los entornos natural o rural (Tabla 3); asimismo, Andalucía se revela como la comunidad autónoma en la que más se utiliza este tipo de espacios para la práctica del CI (Tabla 4). La importancia otorgada al espacio circundante en el CI, y en la danza con improvisación en general, se puede explicar a través de los planteamientos ecologistas subyacentes que promueven el respeto al medio ambiente así como el uso consciente y lúdico de los espacios naturales. Ciertamente, el CI es una práctica centrada en la conciencia corporal que invita a la observación de la repercusión de la propia acción danzada en el movimiento del otro, en el cuerpo del otro, así como en el entorno (Lifschitz 2010). La sensibilidad ambiental y el disfrute corporal en la naturaleza, por tanto, forman parte de sus principios técnicos y metodológicos.

Si nos remitimos a la historia de la danza contemporánea, son conocidas las sedes de experimentación artística que a su vez constituyeron lugares de residencia enmarcados en una granja o en un monte con la pretensión de encontrar en ellos el ambiente idílico, propicio para la creación. Ese fue el caso de La escuela de artes creada por Rudolf Laban en la finca naturista de Monte Veritá, en Suiza entre 1913 y 1918 (Szeemann 2003) y, asimismo, los espacios de danza forestal usados por Anna Halprin en Kentfield (San Francisco) desde los años 60 (Thiberghien 2007). Actualmente, son muchos los espacios artísticos que se adhieren al movimiento ecológico rural; un impulso significativo en Europa ha sido el de la compañía de danza Vértigo en cuya página web reúne las referencias a proyectos similares (<http://sites.ecovillage.org/vertigo-eco-art-village $>$ ). En 
España, como ejemplos de residencia artística en los que el CI ocupó un lugar significativo en sus orígenes, podemos citar las masías de Arlequí (<http://www.arlequi.de/>) en Bañolas o el centro de experimentación corporal L'animal a l'escena $(<\mathrm{http}: / /$ www.lanimal.org/>) en Celrá (Muñoz y Ramis 2013), los dos en la provincia de Gerona. Por otra parte, para la práctica de cursos intensivos de CI como actividad física artístico-educativa o de ocio, hemos observado, además de albergues públicos, como el de Viznar (Granada) o privados como el de Santa María de Miraflores (Burgos), verdaderos oasis de residencia como los cortijos almerienses de El Salvador o de Los baños Alhaman o el espacio de Encuentro, Naturaleza y Creación Baile en el Aire, junto al Parque Natural de Grazalema o La Casa del Búho en la misma región. En el Cortijo de Los baños del Cabo de Gata se ha iniciado en 2015 un Encuentro de Danza Contact y Conciencia Corporal, que se anuncia como "Unas vacaciones diferentes, bailando en el desierto de Tabernas" (<https://desertcontactalmeria.com/>). También desde 2015, el CI forma parte de los contenidos de los cursos de verano organizados por Estivalia una organización colectiva privada que busca el "desarrollo personal y creativo" en parajes hermosos de la naturaleza (<http://www.estivalia.es/\#>) de distintas provincias españolas (La Rioja, Madrid, Cáceres, Salamanca, Ávila, etc.).

En consonancia con el planteamiento de Márcia, De Deus y Olivera (2008: 94), algunas de las prácticas físicas emergentes, en particular las que se realizan en plena naturaleza o en entornos rurales, se integran en los principios ético-políticos del ecoturismo, un concepto de ocio que busca el desarrollo y la autonomía de las poblaciones afectadas y la interacción respetuosa con el entorno con una lógica no necesariamente de mercado. En los espacios de este estudio, que parecen responder a esta intención, observamos la activación de alojamientos de residencia privados o casas rurales abiertas a la realización de eventos grupales en los que se adscriben algunos Encuentros rurales de CI: particularmente, los que se vienen realizando en Garganta La Olla (Cáceres), en la Casona del Uno y en otros espacios del pueblo desde 2012 ( $<$ http://agrandalaolla.org/ blog/even/ii-encuentro-rural-de-contact-improvisacion.html $>$ ); asimismo, los encuentros de La Zarza Dojo en Donillas y de Quintana del Castillo (León), desde 2014 (<http:// www.qevento.es/quintana-del-castillo/iv-encuentro-rural-ci/ $>$ ). Estos eventos, aunque no están exentos de conflictos con el vecindario o con las autoridades locales — pues albergan en ocasiones un número de participantes que supera al de la localidad- visibilizan la hospitalidad de las familias o de los grupos implicados y de los propios municipios que, en ocasiones, acogen las actividades con la cesión, bajo diferentes fórmulas, de espacios sociales polivalentes (Casa de Cultura, Bolera, etc.) así como espacios públicos del entorno (eras, caminos y plazas). A este respecto, Pedro Romero en Ejercicios de ocupación. Afectos, vida y trabajo (2015) subraya, de forma más o menos explícita, cómo los artistas, y en particular los que crean, practican e investigan en torno al cuerpo, utilizan sus propios domicilios y cómo el arte impregna diversos espacios más o menos íntimos.

Otro ejemplo de implicación municipal y local en entornos naturales privilegiados es el de los festivales internacionales de CI organizados los últimos años en las islas de Ibiza y Fuerteventura que, con distintas condiciones de gestión, han utilizado las instalaciones del Campamento de Cala Jondal (<http://ibizacontactfestival.com/es/alojamiento/ $>$ ) y los espacios abiertos del Ayuntamiento de La Oliva (<http://canarian.contactfestival.info/ fuefestival/fuelocations.html $>$ ), respectivamente. Estos exitosos eventos se fueron consolidando con el paso de los años, gracias a la respuesta de participantes de toda Europa. 
En el caso del festival de CI de Ibiza (2008-2015), que el primer año fue una semana de práctica específica de CI, se fue desarrollando con la inclusión de otras prácticas coreográficas afines y, además, con otras técnicas corporales de conciencia y de expresión corporal agrupadas bajo el nombre de onbody: yoga, pilates, acroyoga, feldenkrais, alexander, body mind center, masaje californiano, giroquinesis, etc.

Es un encuentro artístico y social que durante 28 días congrega a más de 500 participantes nacionales e internacionales, en nuestra amada isla de Ibiza. Artistas profesionales, bailarines, amantes del movimiento y la improvisación, gente con ganas de aprender, o simplemente buscadores de nuevas experiencias, vida saludable y naturaleza, son las personas que cada año llenan de vida este festival (<http://ibizacontactfestival.com/es/inicio/>).

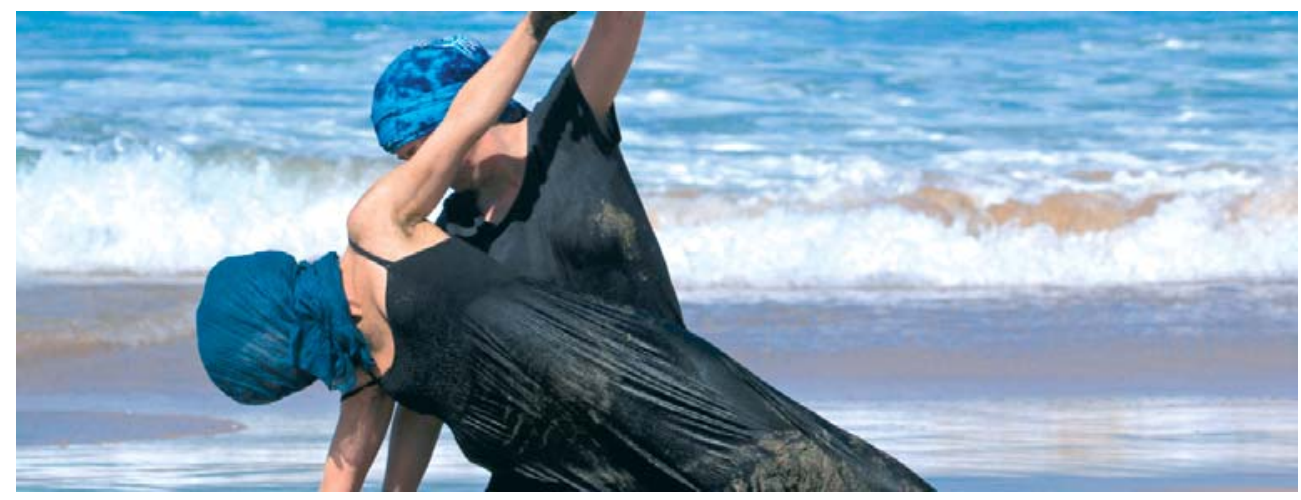

IMAGEN 2.-Fuerteventura CI <http://canarian.contactfestival.info/fuefestival/festival.html>

Asimismo, el deseo y el interés por la interacción con el medio, que no se limita a la contemplación pasiva del paisaje, promueve la relación con el entorno, tanto vegetal como animal; el CI aborda, en este sentido, propuestas de danza junto a los caballos como la que tuvo lugar en el centro de equitación La luz (Alora, Málaga), en la que Virginia Maldonado promueve una práctica que denomina equicontact $(<\mathrm{http}$ ://contactimpromalaga. blogspot.com.es/>) y que Paula Josa-Jones (2011) plantea como exploración de la naturaleza de los cuerpos en el marco de una estrecha interacción creativa con los animales. En este sentido, la práctica del CI se adhiere a la recién denominada eco-somática que engloba un conjunto de prácticas y discursos pedagógicos críticos con el objeto de integrar y confrontar el pensamiento filosófico ecológico de la permacultura con las técnicas y los usos corporales artísticos, educativos y de bienestar social. Puede verse al respecto el ideario del Congreso de prácticas ecosomáticas organizado en el Centro Nacional de la Danza (CND) en Pantin (Francia) en 2014 (<http://natural-movement.fr/files/ CONFERENCES/ecosomatiques/ECOSOMATIQUES_programme.pdf $>$ )

\section{SOLUCIONES URBANAS EN ESPACIOS PÚBLICOS: DANZA EN LA CALLE}

No solo en las localidades o zonas rurales, sino también en los marcos urbanos o en los límites de sus contornos, se utilizan para la danza CI espacios públicos abier- 
tos y zonas verdes en calles, plazas, parques o jardines; esta modalidad se sitúa en un término medio entre los espacios denominados naturales (bosques, montes, playas, desiertos, etc.), los espacios propios de núcleos rurales —en los que se puede acceder de forma inmediata a los anteriores-, y los locales urbanos. Según GarcíaDomenech (2014: 302), "zona verde, plaza o jardín son términos que la ciuda-danía tiende a confundir y que pueden englobarse bajo el común denominador conceptual de espacio público", que se clarifica al añadir "abierto".

La práctica de la danza en la calle, en el caso de la danza contemporánea en general y del CI en particular, se puede asociar más que a la experiencia de aprendizaje regular - como puede ocurrir en otras modalidades de street dance como el break dance en algunos contextos (Gogerly 2012) — a la realización de eventos como jams, o creaciones in situ, que tienden a ser ocasionales o que se combinan con las clases en sitios cerrados. En el contexto español, se ha constatado la realización de jams al aire libre ya en la década experimental de los ochenta (Brozas y García 2014b), pero sobre todo desde finales de los noventa. En este sentido, destaca el grupo de danza improvisada Siamb que en 1999 empezó a organizar jams con distintos formatos en distintos lugares, entre ellos el Parque de Montjuic de Barcelona (<http://siamb.blogspot. com.es/p/siamb_3.html $>$ ). En la misma ciudad, en el 2001, se constata cierta actividad coreográfica por las calles (Brozas 2016: 32) y, en los últimos años, en espacios como la playa de la Barceloneta o el parque de la Ciutadella — donde se ha venido realizando la denominada carton jam (<http://www.contactimprov.es/jams-clases/catalunya/calendario/>) — podemos dar cuenta de una sesión de danza que incluyó la preparación colectiva previa del suelo, con la aportación de un cartón y cinta adhesiva por parte de los participantes. Se pueden señalar otros ejemplos referidos a localidades mediterráneas como Murcia, donde también se han organizado en varias ocasiones jams en la

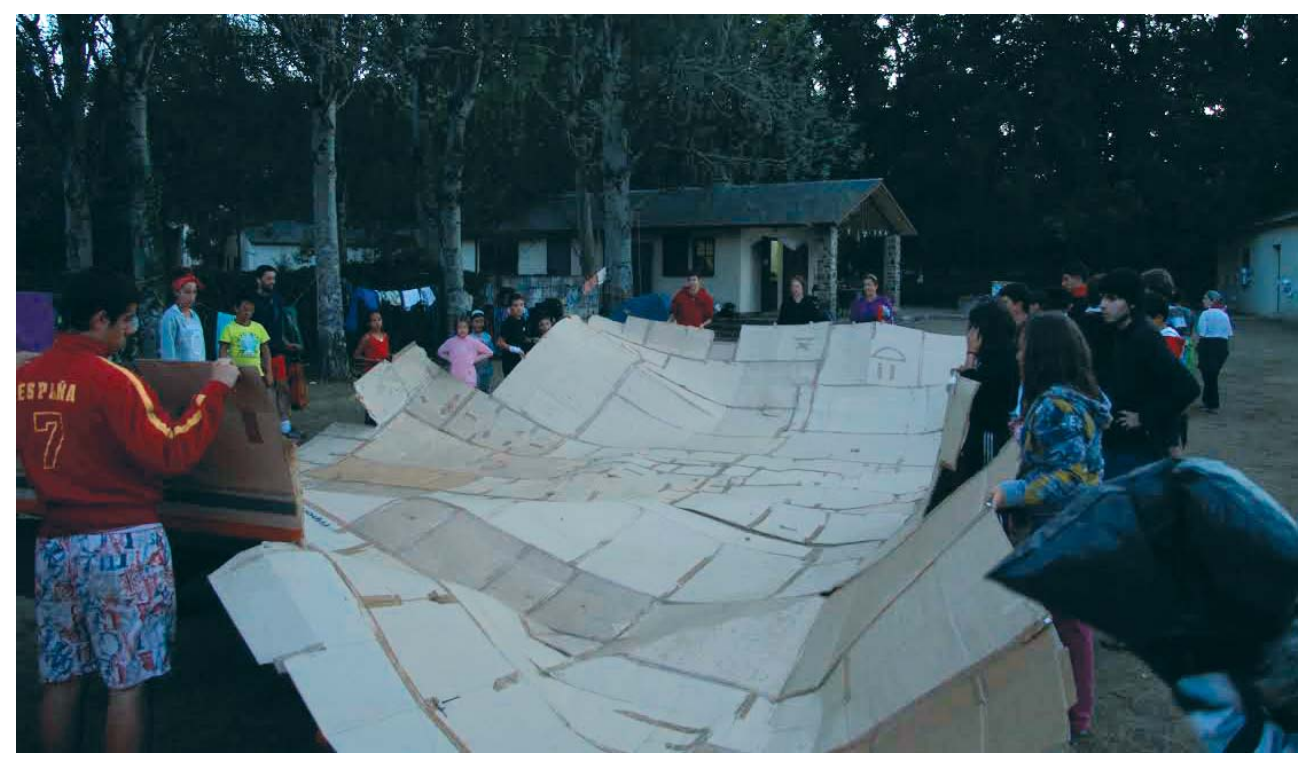

Imagen 3.-Jam en Campamento Scout (Vigo de Sanabria) 2011. Foto Marta Peña Paramio. 
calle y en espacios naturales (R. Herrero, comunicación personal, 8 diciembre 2014), o en Barcelona, en la plaza de San Corneli de Cardedeu, organizada por la asociación As d'arts en 2012. Asimismo, en la zona oeste de la península como es el caso de Badajoz, donde la asociación Experiencia Danza ha utilizado espacios públicos como la Plaza de España o las callejuelas del Casco Antiguo (S. García, comunicación personal, 8 diciembre 2014). En otras ciudades del centro y del norte de la geografía española se han organizado también sesiones abiertas en el marco de alguna festividad, más frecuente en periodo estival; así, por ejemplo, La Noche Blanca en el parque de la Isla en Burgos (Brozas 2013: 113), o más recientemente las jams organizadas en El Barrio de los Artistas en Pamplona, una fiesta anual itinerante ciudadana que lleva el arte a las calles de distintos barrios de la ciudad (<http://www.naiz.eus/media/asset_publics/resources/000/ 293/182/original/programa-Barrio-2016-Cast.pdf >).

Un caso de mayor incidencia, por afectar a distintas ciudades a la vez —Málaga, Badajoz, León y Almería-, fue la acción coreográfica denominada The Big Crunch Project, una manifestación colectiva de arte social en la calle que tuvo lugar en junio de 2015 (<http://thebigcrunch.org/>); un evento similar, de carácter internacional, fue el Global Undescore; propuesto a partir de la iniciativa de bailarines americanos pero que también se realiza en España, al menos desde 2012; se trata de una estructura coreográfica de improvisación que se despliega para bailarse, simultáneamente, en distintos puntos del planeta (<http://globalunderscore.blogspot.com.es/p/blog-page_29.html>).

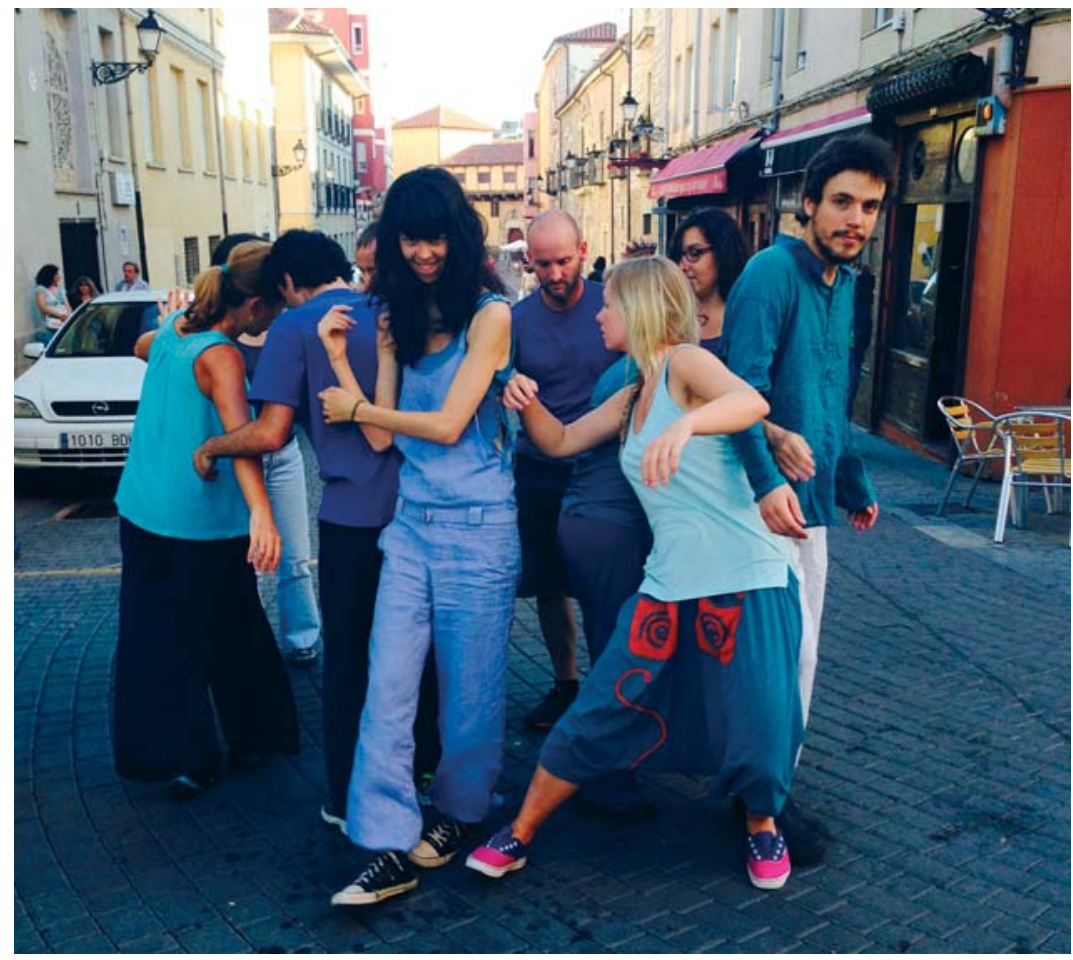

Imagen 4.-Big Crunch Project en las calles de León 2015. Foto Raquel Álvaro. 
La práctica del CI en la ciudad nos remite, de este modo, a una danza in situ, a un espacio público donde se implica a los usuarios habituales de ese espacio, en donde se propone una forma de movimiento en un enclave no escénico en consonancia con el desarrollo del arte contextual que planteaba Pérez Royo (2008) y que revisan, asimismo, Julien Perrin y Ninon Prouteau en la "Conférence sur la danse in situ, in situ" (Prouteau 2008). Anteriormente, Sennet (1997) había señalado al respecto, las dificultades y las resistencias de los espacios urbanos sujetos a intereses económicos y no siempre atentos a la evolución del espacio corporal de convivialidad preciso. En el caso del CI en España, en algunas ocasiones, ciertas exigencias municipales, como la gestión anticipada de permisos en el correspondiente ayuntamiento, puede frenar o dificultar la realización de este tipo de eventos; un ejemplo ha sido el último EMOCIE celebrado en la ciudad de Zaragoza donde no llegaron a tiempo los permisos para las actividades en espacios públicos abiertos que inicialmente estaban previstas (G. Aloni, comunicación personal, 30 noviembre 2016).

En relación con otras actividades físicas lúdicas practicadas en la calle y que permiten la apropiación, transformación y reutilización del espacio público, Saraví (2015: 23) indica, asimismo, cómo su visualización en los grandes centros urbanos puede maravillar a una parte de los viandantes mientras que altera o escandaliza a otra parte, que se puede sentir en ocasiones invadida, afectada o incluso amenazada. La práctica de CI en la calle se aproxima más al tipo de actividades lúdicas espontáneas importunas para el transeúnte que a las reconocidas socialmente como prácticas saludables (Vicente 2010), tales como correr o hacer estiramientos en cualquier acera, arcén o espacio de tránsito, tácitamente aceptadas.

\section{GESTIÓN COLECTIVA DEL ESPACIO: ASOCIACIONES Y ESPACIOS OKUPADOS}

En las tipologías específicas de prácticas artísticas - tanto las propias de la danza como las de otras artes escénicas como el teatro o el circo, de desarrollo más reciente en nuestro contexto (Brozas y Molinero 2015) — y, del mismo modo, en los ámbitos sociales o culturales más generales, se observa la tendencia al asociacionismo para la gestión colectiva de espacios comunes. En el contexto de Castilla y León, desde el Museo de Arte Contemporáneo (MUSAC) en 2013, con la intención de promocionar ese proceso asociativo, se instó la catalogación de "colectivos y espacios culturales independientes" en la comunidad denominado Del mapa al territorio (<http://mapaterritorio.org/>).

A este respecto, mientras que algunos espacios de CI parten de iniciativas individuales (La Puerta Roja, ENEstudio, Escuela Hephaisto, etc.), otros surgen del acuerdo de colectivos que integran varias personas y según diversas perspectivas y orientaciones de trabajo. En este último grupo, es posible que algunos proyectos se integren en espacios públicos muy polivalentes como es el caso del EspacioVías en León, la Danzagunea en Errentería o el Centre Civic La Barceloneta en Barcelona, mientras que otros, son espacios culturales autogestionados que reúnen a varias asociaciones como ocurre en La Fustería de Cardedeu o en El ateneo huertano de Murcia.

La gestión colectiva es frecuente en los espacios de artes escénicas. Entre ellos son muy pujantes los recientemente dedicados al circo; en el registro de este estudio, los seis espacios escénicos circenses que incluyen prácticas de CI se organizan de ese modo 
(Tabla 3) y, ciertamente, las técnicas de circo comparten con el CI una didáctica cooperativa y creativa (Brozas y Vicente 1999) que genera la actividad en grupo.

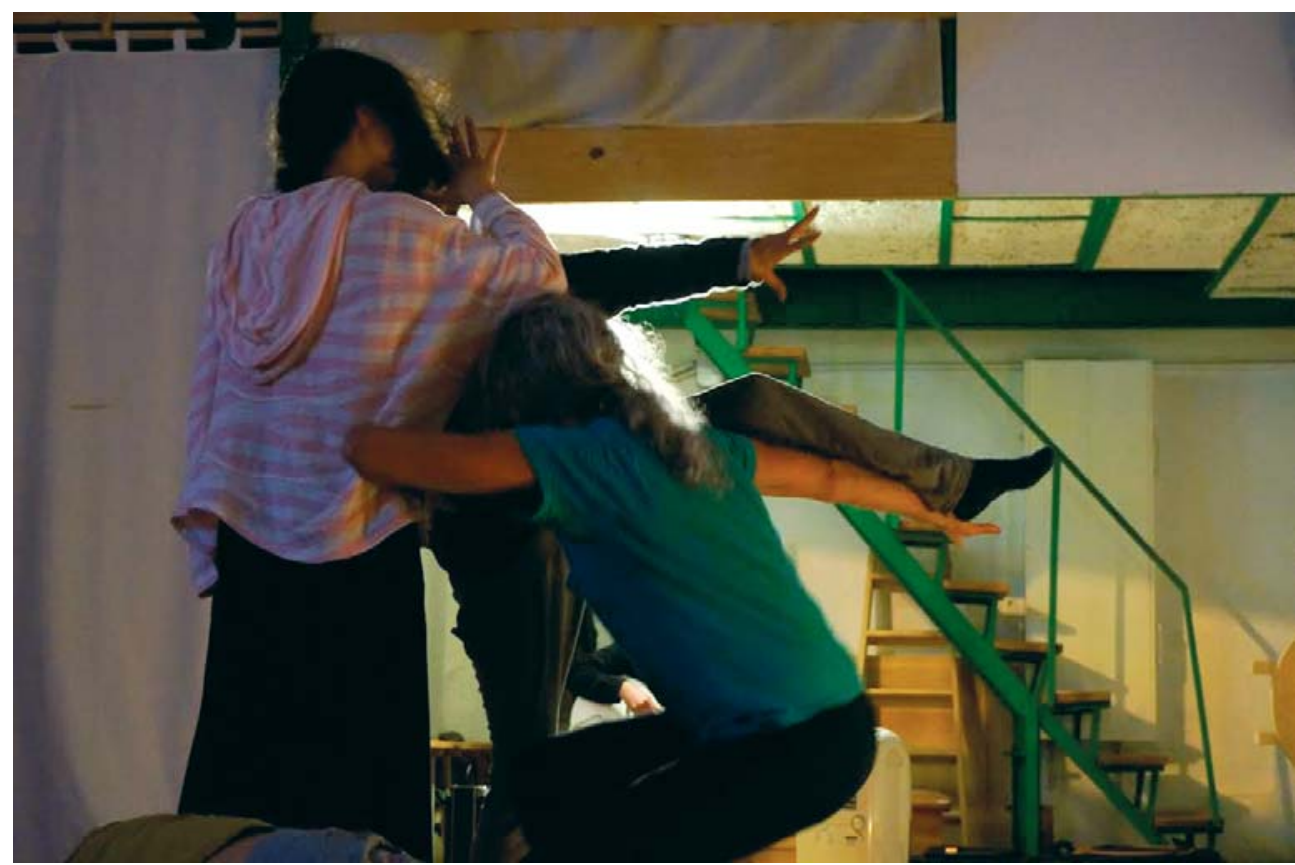

ImAgen 5.-Jam en el Circo bajo el Tejado (Gijón). Foto Irene Álvarez Coto.

En sintonía con el uso colectivo, una forma genuina de utilización y gestión de los espacios públicos y privados, afectada por la práctica de CI y de circo, entre otras prácticas artísticas, es la de los espacios okupados. Es el caso de la Sala Molino Rojo de La Tabacalera, donde se realizan tanto cabarets de circo como jams de CI (<www.latabakalera.net $>$ ). La Tabacalera, antigua fábrica de tabaco del barrio de Embajadores en Madrid, que funciona desde 2012, es señalada por Gómez (2013: 208) como ejemplo de un espacio social autogestionado intervenido por plataformas subculturales y contraculturales y, al mismo tiempo, catalogado como bien de interés cultural adscrito al Ministerio de Cultura; de hecho, una parte de sus dependencias acogen exhibiciones programadas por la institución ministerial. Aunque es La Tabacalera un espacio llamativo y duradero, son varios los casos de espacios okupados que durante algún tiempo han acogido, tanto en contextos rurales como urbanos, la práctica de CI en otras localidades como Barcelona (Can Masdeu), Bilbao o Mallorca y que, en ocasiones, fueron desalojados o trasladados. En la ciudad de Palma de Mallorca, según Simón Malone (comunicación personal, 27 enero 2015), funcionaron, entre 2010 y 2012, los Centros Sociales Ocupados (CSOA) El Resplandor y Sa Foneta para la organización de jams de CI: El Resplandor era un viejo hostal de prostitutas y Sa Foneta un bloque de pisos que se utilizó durante la ocupación de la Plaça Espanya en las asambleas del 15-M. 


\section{ESPACIOS INSTITUCIONALES: DANZA, EDUCACIÓN Y CI}

Desde sus inicios, el CI se ha autodefinido como una práctica resistente en la medida en que plantea cierta ruptura de valores y métodos respecto de las formas preponderantes de entrenamiento y creación corporal más representativas, no solo del mercado, sino también de las instituciones educativas (Paxton 1993: 65); sin embargo, también desde los inicios, ha ocupado los espacios de estas. De hecho, los primeros experimentos pedagógicos que facilitaron la concepción de esta forma de danza se realizaron en el Warner Main Space, un enorme gimnasio donde Steve Paxton enseñó las habilidades germinales del CI en enero de 1972 en el Oberlin College, universidad privada de artes liberales fundada en 1833. Se trata de un espacio universitario en el que, aún hoy, una enorme comunidad de estudiantes y bailarines sigue practicando, gracias al impulso de profesoras como Ann Cooper Albrigth.

Today the space feels like a big attic —old, woody, slightly airless — one whose contents have evaporated over time so that only the dust, memories, and ghosts of a ship, an old swimming pool, a Roman amphitheater, and a huge, but comfy, womb. The space I am describing is a Warner Main Space, unquestionably one of the most beautiful dance studios in the world. I have danced in this space at sunrise and at sunset. I have danced here throughout all the seasons of the year; in storms and in fair weather. I know the magical effects almost every inch of the wonderfully responsive floor (which is like a trampoline). I have danced in this space alone and with over 300 people. (...) This is just one example of the kind of energy that reverberates in the space. These days, I consider it home - a place of dwelling in which I feel most fully present. It is also the home of one of the most vibrant contact improvisation communities in any university setting [...] (Albright 2013: 212).

\begin{tabular}{|c|c|}
\hline NOMBRE Y LUGAR & ACTIVIDADES Y FECHAS \\
\hline \multicolumn{2}{|c|}{ Educación Infantil y Primaria } \\
\hline $\begin{array}{l}\text { Xantala. Espacio de Educación Libre } \\
\text { (Barcelona) }\end{array}$ & $\begin{array}{c}\text { Jams, intensivos, laboratorio semanal } \\
(2014,2015)\end{array}$ \\
\hline $\begin{array}{l}\text { Colegio Dolors Granell } \\
\text { (Cardedeu, Barcelona) }\end{array}$ & $\begin{array}{l}\text { Clases en Festival de Danza Improvisada } \\
(2014,2015)\end{array}$ \\
\hline CP. Atakondoa (Irurtzun, Navarra) & $\begin{array}{l}\text { Clases y jam II Encuentro de CI País Vasco } \\
2015\end{array}$ \\
\hline Colegio Concertado Leonardo da Vinci (Murcia) & Jams 2012 \\
\hline CP Villanueva de Pría (Asturias) & Intensivo 2011 \\
\hline \multicolumn{2}{|c|}{ Educación Secundaria } \\
\hline IES de Astorga (León) & CI en el Proyecto de Aula, 2014-2015 \\
\hline IES Castellar (Badajoz) & Jams, talleres. 2010-2015 \\
\hline IES Los Salados (Benavente, Zamora) & $\begin{array}{l}\text { Seminario de CI para profesores de EF. } \\
\qquad 2012-2015\end{array}$ \\
\hline IES Río Duero (Zamora) & Intensivo 2012 \\
\hline IES Manuel Losada (Carmona, Sevilla) & Jam 2012 \\
\hline \multicolumn{2}{|c|}{ Educación universitaria } \\
\hline Aula de Artes del Cuerpo ULE & Clases, intensivos y jams, (2010-2015) \\
\hline Aula de Danza UCO (Córdoba) & Intensivos (desde 2012) \\
\hline Escuela Universitaria de Zamora (U. Salamanca) & Intensivos en Jornadas de Expresión Corporal \\
\hline Universidad de Valladolid & Curso Extensión Universitaria 2013 \\
\hline INEFC Lleida & Estudios experimentales 2012 \\
\hline
\end{tabular}

TABla 5.-Muestra de centros educativos en España con actividades de CI (2010-2015). 


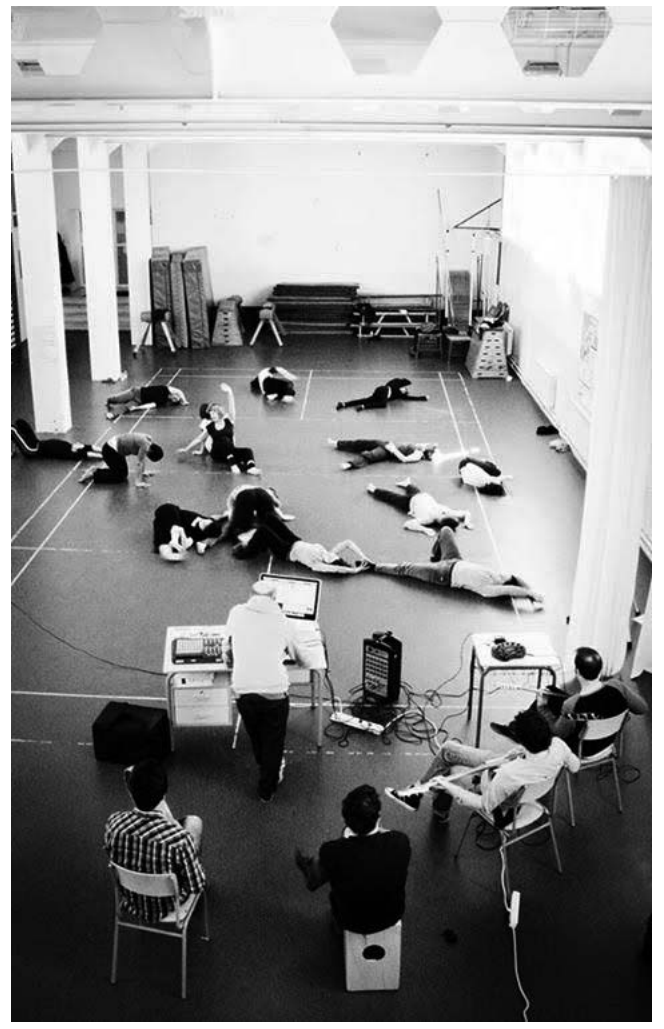

IMAGEN 6.-Jam en el IES Castellar (Badajoz). Cortesía de Experiencia Danza.

Asimismo, en los ochenta, la expansión del CI en Europa se produce gracias a espacios educativos singulares como el Dartington College, donde en 1986 Steve Paxton fundó, junto a Ann Kilkoyne, el proyecto Touchdown que facilitaba el aprendizaje de CI a un grupo de bailarines con discapacidades visuales junto a un grupo de estudiantes de danza (Paxton, Kilcoyne y Mount 1993). El proyecto continúa desde 1996 en un centro de arte de Manchester bajo la dirección de Katy Dymoke (2014) y actualmente se denomina Touchdown Dance (<http://www.touchdowndance. co.uk/?page_id=58>).

En el contexto español, el registro de espacios escolares de las distintas etapas (Tabla 5) indica un uso puntual derivado casi exclusivamente de la organización de cursos intensivos organizados en centros escolares, tanto de educación primaria como de secundaria y de enseñanza universitaria; en algunos institutos, donde trabajan profesores de Educación Física conocedores del CI, se han utilizado de forma regular a lo largo de varios años para la realización de seminarios pedagógicos. Tenemos constancia del IES Los Salados en Benavente (Zamora) y de jams de CI en el IES Castellar en Badajoz; asimismo, de la existencia de proyectos educativos artísticos de CI en el IES Astorga (León). A este respecto, Débora Borque, en su reciente tesis doctoral, hace referencia a algunas de las experiencias y planteamientos educativos de nuestro contexto que incluyen la práctica de CI (Borque 2015). En algunos Institutos de Educación Física o facultades de Ciencias de la Actividad Física y del Deporte se realizan actividades formativas regulares de CI, como ocurre en la Universidad de León, pero generalmente se trata de cursos de extensión universitaria intensivos así como de concretas residencias de investigación que han permitido estudios didácticos como los de Castañer y Torrents (2008), Castañer et al. (2009) y Torrents (2010 y 2013).

Por otra parte, es preciso, referirse a la creciente, controvertida y a veces invisible presencia del CI en los espacios de formación profesional. Nuestra recogida de datos pone de manifiesto cómo algunos Conservatorios de Danza han acogido actividades formativas como cursos intensivos o Festivales de CI; este es el caso del Conservatorio de Málaga y de los Conservatorios de Madrid Mariemma y María de Ávila (véanse Tablas 1 y 3). Estamos de acuerdo con Eva López-Crevillén (comunicación personal, 18 febrero 2016), profesora del Conservatorio Superior de Danza María de Ávila, en 
que sería necesario un estudio específico sobre la presencia del CI en las enseñanzas de danza en España, recorriendo cada uno de los centros y entrevistando al profesorado, pues en los Planes de Estudio no hay referencias explícitas al CI. Sin embargo, en el caso del Conservatorio de Danza María de Ávila, a través de la entrevista, se constata cómo la presencia del CI es múltiple y creciente; forma parte de Técnicas de Danza y más ocasionalmente de Talleres de Interpretación, asignaturas ambas que estudian los alumnos y alumnas de los estilos de Danza Clásica y Danza Contemporánea; en esta última se estudia en diferentes cursos junto a otras técnicas, generalmente impartido por profesores externos. El CI también ha estado presente en las asignaturas de Metodología y Didáctica así como en Danza educativa y comunitaria de la especialidad de Pedagogía de la Danza. A este respecto, se ha desarrollado un acuerdo entre el Conservatorio y la Academia de San Fernando con la colaboración de Marisa Brugarolas, que utiliza el CI como recurso pedagógico en su propuesta de Danza Inclusiva (Brugarolas 2015). Este ejemplo pone de manifiesto las posibles direcciones de aplicación del CI en el contexto de la formación superior en danza.

La cuestión de la presencia del CI en las instituciones de danza en España y su influencia en el desarrollo reciente de la danza contemporánea suscita cierta controversia. La polémica, que ya se manifestó en el EMOCIE celebrado en Cáceres en 2012 en torno al Institut del Teatre - centro pionero en la enseñanza de la Danza Contemporánea en el territorio español (Vendrell 2008)—, parece persistir en el momento actual. Algunas estudiantes y profesoras de danza consideran que la presencia del CI es importante en la formación de danza contemporánea desde los años 90 hasta hoy (S. García, comunicación personal, 9 diciembre 2012; E. López-Crevillén, comunicación personal de 18 de febrero de 2016), mientras otros consideran que no ha tenido la suficiente autonomía ni consideración como forma de danza (R. Roig, comunicación personal, 25 marzo 2014; D. Bonilla, comunicación personal, 20 febrero 2015). Ciertamente, en el Institut del Teatre se llegaron a elaborar proyectos de impartición de CI como asignatura, siguiendo el modelo de otras instituciones europeas como la School for New Dance de Amsterdam (Fabius 2010) pero no fueron aprobados (E. Momblant, comunicación personal, 12 diciembre 2013).

Finalmente, cabe señalar la desconfianza y rechazo de aquellos practicantes del CI que, próximos a un ideario libertario o contracultural, muestran hacia el modelo de clases regulares y formales en centros de danza establecidos ad hoc una reticencia que es a menudo recíproca por parte de los estudiantes de otras formas de danza hacia los practicantes de CI y que impide un mejor aprovechamiento de las posibilidades de intercambio entre unos y otros practicantes de danza (J. Planelles, comunicación personal, 10 febrero 2015).

\section{ESPACIOS PRIVADOS DE TERAPIA Y BIENESTAR: WELLNESS Y MINDFULNESS}

Un caso particular y reciente de espacios de práctica de CI lo constituyen los centros de salud y/o de bienestar; se trata de un ámbito de llamativo crecimiento en nuestro contexto (Albert 2015: 356) que se caracteriza por el uso de técnicas corporales de atención, meditación y conciencia (mindfulness). Nuestro estudio permite constatar que la expansión de este tipo de prácticas no se circunscribe a los sitios específicos de ense- 
ñanza y práctica de Yoga o Pilates o a los catalogados como de bienestar (wellness) y mantenimiento de la forma (fitness); tampoco se restringen al grupo específico de espacios de terapia, que iguala en número a los de educación (Tabla 3). Observamos que estas técnicas de conciencia corporal, con las que confluye y mimetiza el CI, forman parte de las propuestas que se incardinan en el medio natural y en los espacios de danza, como se ha explicado en párrafos anteriores. El diálogo de la danza CI con otras técnicas de conciencia corporal, también denominadas técnicas de movimiento somático, lo atribuye Louppe (2011: 78) al estado de meditación propio la danza contemporánea situada en un paradigma de "cuerpo en devenir" que sustituye al "cuerpo dado". Suquet (2006: 397), a este respecto, se refiere al CI como una forma coreográfica que constituye la quintaesencia de la aspiración perceptiva de la danza a lo largo de todo el siglo XX.

En el marco de la evolución del CI en el contexto de los estudios, lugares emblemáticos de práctica como Estudio3 en Madrid (Brozas 2016: 32) indican un fructífero y complejo encuentro entre tres perspectivas: la derivada de las artes escénicas, la de la danza y la del desarrollo personal, promovido este por Antonio del Olmo a finales de los años 90. Este profesor desarrolló la aplicación del CI con una orientación terapéutica en la que convergen otras prácticas y otros profesionales especializados en el bienestar lo que, a su vez, hace que el CI quede de alguna forma diluido en espacios heterónomos, tanto educativos como artísticos (Tabla 3). Un ejemplo, en este sentido, es el tipo de propuestas de arte-terapia-educación que se realizan en el Albergue de Viznar (Granada), también desde los años 90 hasta hoy. Entre los lugares señalados como terapéuticos, algunos autodenominados de desarrollo, el CI aparece como una práctica más o menos ocasional, integrada en un conjunto de técnicas psico-corporales y de sensibilidad artística. Sin embargo, artistas pioneras en la práctica del CI y en la improvisación en la escena, aunque reconocen la importancia del acercamiento entre los cuerpos de los bailarines y, sobre todo, el despertar de la conciencia del movimiento, como grandes aportaciones del CI a la danza contemporánea, expresan su distanciamiento respecto de los espacios y de las concepciones terapéuticas o de bienestar: "Nosotras estamos en el mundo de la acción, no en el mundo del bienestar personal» (M. A. Oliver, comunicación personal, 4 febrero 2011).

\section{CONSIDERACIONES FINALES}

Este artículo, a partir del sondeo y clasificación de los lugares donde se practica CI en el contexto español, busca informar de la evolución de prácticas corporales contemporáneas en cuyo seno el arte dialoga con otros ámbitos culturales a través de los lugares que comparten. La proliferación de algunas prácticas, en particular las relacionadas con emergentes movimientos físico-psico-espirituales (Albert 2015), conlleva la ocupación y creación de múltiples espacios, más o menos efímeros, que modifican constantemente los formatos y las propuestas.

Cada espacio cubre unas necesidades, tiene unas limitaciones y está sujeto a unas condiciones sociopolíticas, históricas y/o económicas; pero, precisamente por esto, la riqueza de un tejido cultural vivo se puede relacionar con la existencia de todo tipo de espacios, desde los más autogestionados, autofinanciados e independientes hasta los más institucionalizados y subvencionados (Pérez 2014: 183). 
Con el estudio hemos constatado que, en el contexto español, las imparables iniciativas para el aprovechamiento de espacios privados, en particular los rurales, no solo dirigidos a la danza sino a otras muchas actividades físicas artísticas, de conciencia corporal, de relación grupal o de contacto con la naturaleza, constituyen un caldo de cultivo de hibridación de prácticas y configuración de espacios. En los núcleos urbanos predominan los centros de desarrollo o de salud donde el CI ha encontrado espacio junto a prácticas específicamente psicoterapéuticas. Asimismo, se evidencia la existencia de propuestas en el seno de espacios públicos e institucionales, sobre todo educativos; de donde se desprende un particular vínculo del CI con el área de la educación física.

El referente artístico y coreográfico de donde surgió el CI sigue siendo fundamental y continúa desarrollándose, aunque aparezca como uno más, entre los múltiples enfoques de su práctica. Como técnica de danza o herramienta de creación escénica, su presencia es más invisible pues no se indica expresamente en la mayoría de los casos; esta podría considerarse una limitación metodológica del estudio puesto que hemos utilizado como criterio para el registro de espacios de CI la indicación explícita del término. Sería deseable, por ello, otras investigaciones ulteriores que ahondaran de forma más local y con mayor profundidad, tanto en la formación profesional en la danza como en la evolución de los procesos de creación.

La tipología de los lugares inventariados revela la amplitud de actividades formativas que se formulan y generan en torno al CI (cursos, clases, jams, encuentros, seminarios, festivales, ensayos, laboratorios, espectáculos o performances) con usos espaciales a veces diferenciados. Este abanico de propuestas enfatiza la divergencia en las concepciones de esta danza, que se comprende y organiza tanto en paradigmas de creación artística, educativa o terapéutica, como en el marco de las emergentes prácticas colectivas de convivencia, de conciencia y/o de relación con el entorno natural. La selección de los espacios también permite detectar el espectro poblacional que incluye actualmente la participación de la población infantil mediante propuestas a veces de carácter familiar, hasta el momento apenas involucrado en la danza contemporánea pero que está creciendo en paralelo con lo que sucede en otras latitudes europeas y americanas (Morales 2014).

Se podría, así, definir el CI como una práctica posmoderna, acorde con las nuevas tendencias de la actividad física, en la medida en que se adhiere a los principios ecologistas, activistas, neofeministas y creativos que plantean, sobre todo, cierta resistencia a la mercantilización del cuerpo y a los parámetros de la modernidad los cuales, en todo caso, siguen imperando en las prácticas corporales dominantes (Águila 2007; Águila y Sicilia 2014; Curtis 2015).

El CI, para finalizar, forma parte de un grupo de actividades que cuestiona los modelos corporales hegemónicos que se construye, con esfuerzo, en una constante y creativa exploración de métodos y fórmulas de asociación e inserción social al tiempo que se integra, a través de los espacios que lo sostienen, tanto en la lógica de las instituciones como en algunas dinámicas de la economía de mercado. El CI no constituye una técnica-pedagogía unívoca e independiente del devenir de las demás técnicas corporales contemporáneas: fruto de un paradigma artístico y sociopolítico concreto, pervive, sin embargo, alimentándose de las otras prácticas y saberes con los que cohabita en los lugares donde se practica. Como técnica corporal compleja y permeable, 
incorpora modos de hacer así como discursos que se reformulan en distintas direcciones los cuales, a su vez, interpretan de forma diversa los distintos cuerpos en danza; una danza que se inscribe en cada espacio y que se ve impregnada a la vez por los códigos culturales de la arquitectura o el paisaje donde se despliega.

\section{ANEXOS}

Los siguientes anexos están disponibles en la versión en línea de este artículo:

ANEXO 1.-Espacios practicados por la autora como bailarina estudiante o profesora de danza CI.

ANEXo 2.--Referencias de espacios con práctica de CI en España hasta 2015.

\section{BIBLIOGRAFÍA CITADA}

Águila, Cornelio. 2007. "Las actividades físicas de aventura en la naturaleza: ¿un fenómeno moderno o posmoderno?". Apunts Educación Física y Deportes 89: 81-87.

Águila, Cornelio y Álvaro Sicilia. 2014. "La actividad física en España ante la dialéctica modernidadposmodernidad: el caso de los centros de fitness". Movimiento 20(3): 1223-1242. Disponible en: $<$ http://seer.ufrgs.br/index.php/Movimento/article/view/43859/31607>. Fecha de acceso: 08 jul. 2016.

Albert, María. 2015. “Yoga en España. Proceso de regulación profesional”. Revista de Dialectología y Tradiciones Populares 70(2): 355-377.

Albright, Ann C. 2013. Engaging Bodies. The Politics and Poetics of Corporeality. Middletown: Wesleylan University Press.

Ballesteros, Jesús. 2000 [1989]. Posmodernidad: decadencia o resistencia. Madrid: Tecnos.

Banes, Sally. 2002. Terpsicore en baskets. Post-modern dance. París: Chiron.

Becker, Carolina. 2009. "Contact on Mallorca". Contact Quarterly 34(2): 47.

Borque, Déborah. 2015. Antecedentes artísticos de la danza Contact Improvisation: visiones educativas de los contacters. Tesis doctoral inédita. Madrid: Departamento de Didáctica de la Expresión Plástica, Facultad de Bellas Artes de la Universidad Complutense de Madrid.

Boullosa, Mónica y Víctor Montes. 2011. "Danza con el tacto”. Disponible en: <http://cusamaco.eu/ contact-improvisacion/>. Fecha de acceso: 24 oct. 2016.

Brozas, María Paz. 2000. "Contact Improvisation: danza, acrobacia y pedagogía corporal", en J.P. Fuentes y M. Macías (eds.), Actas I Congreso de la Asociación Española de Ciencias del Deporte: 309-316. Cáceres: Universidad de Extremadura.

Brozas, María Paz. 2013. "La accesibilidad en la danza Contact Improvisation". Arte y Movimiento 8: [s. p.]. Disponible en <http://revistaselectronicas.ujaen.es/index.php/artymov/article/view/919>. Fecha de acceso: 20 sep. 2016.

Brozas, María Paz. 2014. "Naturaleza estética y pedagógica de las jams de danza Contact Improvisation en España". Cuerpo, cultura y deporte 26(9): 107-118. doi: 10.12800/ccd.v9i26.429

Brozas, María Paz. 2016. "Expansión geográfica y conceptual de la danza Contact Improvisation en España (1990-2000)". Retos. Nuevas tendencias en educación física, deporte y educación 30: 3035. Disponible en: <https://dialnet.unirioja.es/descarga/articulo/5390981.pdf>. Fecha de acceso: 08 ene. 2016.

Brozas, María Paz y Teresa García. 2014a. "Contact Improvisation in Spain. Dance, body and geography. A study lab at the Contact Festival Freiburg 2009". Contact Quarterly Webtext 39(1): [s. p.]. Disponible en: <https://contactquarterly.com/contact-improvisation/newsletter/view/ci-inspain\#\$>. Fecha de acceso: 14 feb. 2014. 
Brozas, María Paz y Teresa García. 2014b. "Los comienzos de la danza Contact Improvisation en España (1980-1990)". Revista Internacional de Medicina y Ciencias de la Actividad Física y del Deporte 53(14): 169-181. Disponible en: <http://cdeporte.rediris.es/revista/revista53/artcomienzos433.htm>. Fecha de acceso: 02 feb. 2017.

Brozas, María Paz y Miguel Molinero. 2015. Telas Aéreas: cuaderno de aprendizaje. León: Universidad de León.

Brozas, María Paz y Miguel Vicente. 1999. Actividades acrobáticas grupales y creativdad. Madrid: Gymnos.

Brozas, María Paz, Idoya Zabaleta y Leticia Morales. 2001. "Contact Improvisation: bases pedagógicas", en Curso de Verano del INEF de Castilla y León: 27-38. Valladolid: Junta de Castilla y León.

Brugarolas, M..$^{\text {a }}$ Luisa. 2015. "Contact Improvisation", en M. ${ }^{\text {a }}$ Luisa Brugarolas, El cuerpo plural. Danza integrada en la inclusión. Una renovación de la mirada: 313-325. Tesis doctoral. Universidad de Valencia: Departamento de Escultura. doi: 10.4995/Thesis/10251/62203

Castañer, Marta y Carlota Torrents. 2008. "Educación integral mediante el Contact Improvisation". Tándem. Didáctica de la Educación Física 26: 91-100.

Castañer, Marta, Carlota Torrents, María Disunova y Teresa Anguera. 2009. "Instrumentos de observación ad hoc para el análisis de las acciones motrices en Danza Contemporánea, Expresión Corporal y Danza Contact-Improvisation. Apunts, Educación Física y Deportes 96: 14-23.

Certeau, Michel. 2000. La invención de lo cotidiano y artes de hacer. México: Universidad Iberoamericana.

Curtis, Jess. 2015. "Movement in the Men's movement: Contact Improvisation and social change". Journal of Dance E Somatic Practices 7(2): 129-142. doi: 10.1386/jdsp.7.1.129_1

Dymoke, Katy. 2014. "Contact improvisation, the non-eroticized touch in an "art-sport". Journal of Dance \& Somatic Practices 6(2): 205-218. doi:10.1386/jdsp.6.2.205_1

Fabius, Jeroen. 2010. "Esa desconocida, la danza por hacer. Ideas más destacadas en 30 años de educación de danza en la School for New Dance". Cairon, Revista de Estudios de Danza 13: 189-202.

Foucault, Michel. 2009. Le corps utopique, Les bétérotopies. Clamecy: Nouvelles Éditions Lignes.

García-Doménech, Sergio. 2014. "Percepción social y estética del espacio público urbano en la sociedad contemporánea". Arte, Individuo y Sociedad 26(2): 301-305.

Gil, José. 2001. Movimiento total. O corpo e a danca. Lisboa: Relogio d'agua.

Gimeno, Patricia (2014). "The Magic Moment. Aplicación de la teoría del Flow a la práctica del Contact Improvisation para el refuerzo de la autoconfianza", en Carmen Giménez (ed.), La investigación en Danza en España 2014: 419-428. Valencia: Ediciones Mahali.

Gogerly, Liz. 2012. Street Dance. Minneapolis: Lerner Publications Company.

Gómez, Rafael. 2013. "La estética de la rebeldía: del situacionismo a la okupación". Arte y Ciudad : Revista de Investigación, extra 3.1: 199-214. Disponible en: <http://www.arteyciudad.com/revista/index.php/num1/article/view/116/263>. Fecha de acceso: 07 oct. 2016.

Josa-Jones, Paula. 2011. "Common body, the dancer, the horse". Contact Quarterly 36(1): 13-19.

Le Breton, David. 1991. Corps et societés. Essai de sociologie et d'anthropologie du corps. París: Meridiens Klinscksieck.

Lefebvre, André. 2013 [1974]. La producción del espacio. Madrid: Capitán Swing.

Lifschitz, Mariana. 2010. Permiso para bailar. Un documental sobre Contact Improvisation. Documental. Buenos Aires: La noche del cine.

Louppe, Laurence. 2011. Poética de la danza contemporánea. Salamanca: Universidad de Salamanca.

Maldonado, Virginia. 2013. "Contact in Málaga, Spain”. Contact Quarterly 38(1): [s. p.]. Disponible en: <https://contactquarterly.com/contact-improvisation/newsletter/view/contact-in-malagaspain\#\$>. Fecha de acceso: 02 abr. 2016.

Márcia, Ana, Humberto L. De Deus y Javier Olivera. 2008. «El crecimiento del ecoturismo y de las actividades físicas de aventura en la naturaleza (AFAN): elementos para comprender la situación actual en España y Brasil". Apunts. Educación Física y Deportes 94: 45-53.

Mauss, Marcel. 1979. "Concepto de la técnica corporal”, en Sociología y Antropología: 337-356. Madrid: Tecnos. 
Melguizo, Javier. 2010. "Bailando contact". Disponible en: <http://www.javiermelguizo.com/ integracioncreadora_textos5.html >. Fecha de acceso: 21 abr. 2015.

Milstein, Diana y Héctor Mendes. 1999. La escuela en el cuerpo. Madrid: Miño y Dávila.

Muñoz, María y Pep Ramis (eds). 2013. "Sobre la vida en este lugar", en Swimming Horses: 62-63. Gerona: Mal Pelo.

Morales, Leticia. 2014. "Danza en familia: un juego entre padres e hijos". Mini Danza. Revista especializada en danza infantil. Disponible en: <https://minidanzarevista.wordpress.com/2014/03/ 25/danza-en-familia-un-juego-entre-padres-e-hijos/>. Fecha de acceso: 28 oct 2016.

Novack, Cynthia. 1990. Sharing the Dance, contact improvisation and American culture. Madinson: University of Wisconsin Press.

Padilla, Carmen y Yolanda Hermoso. 2002. "De la danza improvisación a la danza contacto". Disponible en: <http://www.expresiva.org/wp-content/uploads/2015/02/X009_De_la_danza_improvisacion.pdf >. Fecha de acceso: 23 oct. 2016. Originalmente publicada en: EducaÇao Física. AssociaÇao de profissionais de EducaÇao Física 1-2: 43-47.

Padilla, Carmen y Raquel Zurdo. 2009. "Desarrollo de la creatividad a través de la danza improvisación y la danza contacto. Valores y aplicaciones en educación primaria y secundaria", en Kiki Ruano y Galo Sánchez (eds.), Expresión corporal y educación: 217-258. Sevilla: Wanceulen.

Paxton, Steve. 1993. "Drafting interior techniques". Contact Quarterly 18(1): 64-78.

Paxton, Steve, Anne Kilcoyne y Kate Mount. 1993. "On the Braille in the Body: An Account of the Touchdown Dance Integrated Workshops with Visually Impaired and the Sighted.. Dance Research 11(1): 3-51.

Pérez, Aimar. 2014. "Entrevista de Manuel Olveira a Aimar Pérez Gali", en Manuel Olveira (ed.), Conferencia performativa. Nuevos formatos, lugares, prácticas y comportamientos artísticos: 175188. León: Museo de Arte Contemporáneo de Castilla y León.

Pérez Royo, Victoria (ed.). 2008. ¡A bailar a la calle! Danza contemporánea, espacio público y arquitectura. Salamanca: Ediciones Universidad de Salamanca.

Prost, Antoine. (1992). "Fronteras y espacios de lo privado", en Philippe Airès y Georges Duby (eds.), Historia de la vida privada. La vida privada en el siglo XX: 13-153. Madrid: Taurus.

Prouteau, Nino. (2008). "Conférence sur la danse in situ, in situ". Documento académico inédito. Disponible en: <http://www.danse.univ-paris8.fr/>. Fecha de acceso: 3 nov. 2016.

Romero, Pedro. 2015. "Tres excursiones. Formulaciones en torno a los efectos y afectos de la danza y el baile", en Ixiar Rozas y Quim Pujol (eds.), Ejercicios de ocupación. Afectos, vida y trabajo: 251-266. Barcelona: Mercat de les Flors.

Saraví, Jorge. R. 2015. "Prácticas corporales urbanas y Educación Física: nuevos desafíos y posibilidades", en A.F. Rodríguez, J.R. Tobar y D.M. Olivares (eds.), Educación Física y Ciencias del Deporte. Guayaquil: CIDE.

Sennet, Richard (1997). Carne y piedra. El cuerpo y la ciudad en la civilización occidental. Madrid: Alianza Editorial.

Suquet, Annie. 2006. "El cuerpo danzante: un laboratorio de la percepción", en Historia del cuerpo: el siglo $X X$, vol. 3: 379-399. Madrid: Taurus.

Szeemann, Harald. 2003. "Monte Veritá", en Claire Rousier (ed.). Ettre ensemble. Figures de la communauté en danse depuis le XXe siècle: 17-40. Pantin: Centre national de la danse.

Thiberghien, Gilles. 2007. "Lawrence Halprin: danse et movement du monde». Les carnet du paysage 13-14: 48-63.

Torrents, Carlota, Marta Castañer, María Dinunova y María Anguera. 2010. "Discovering new ways of moving: observational analysis of motor creativity while dancing contact improvisation and the influence of the partner.. Journal of Creative Behavior 44(1): 45-61.

Torrents, Carlota, Robert Hristovski y Natàlia Balagué i Senre (2013). "Creatividad y emergencia espontánea de habilidades de danza". Retos. Nuevas tendencias en Educación Física, Deporte y Recreación 24: 129-134.

Vendrell, Esther. 2008. "La contemporaneidad coreográfica en Catalunya: una expresión de la etapa democrática de fin de siglo". Assaig de teatre: revista de l'Associació d'Investigació $i$ Experimentació Teatral 232: 68-69. Disponible en <http://www.raco.cat/index.php/assaigteatre/article/viewFile/ 182686/235353>. Fecha de acceso: 4 nov. 2016. 
Vicente, Miguel. 2010. "La construcción social del cuerpo sano. El estilo de vida saludable y de las prácticas corporales de la forma como exclusión". Nómadas. Revista Crítica de Ciencias Sociales y Jurídicas 28(4): 119-145.

Zurdo, Raquel. 2005. "La improvisación de la Danza Contacto o la libertad de danzar", en Actas de las II Jornadas Regionales de Expresión Corporal: 101-113. Cádiz: Asociación Gaditana de Docentes de Educación Física.

Zurdo, Raquel. 2008. "Danzando con-tacto", en Galo Sánchez, Javier Coterón, Javier Gil y Antonio Sánchez (eds.), El movimiento expresivo: 205-210. Salamanca: Amarú.

Fecha de recepción: 17 de noviembre de 2016

Fecha de aceptación: 18 de julio de 2017 

Revista de Dialectología y Tradiciones Populares, vol. LXXII, n. ${ }^{\circ}$ 2, pp. A1-A8, julio-diciembre 2017, ISSN: 0034-7981, eISSN: 1988-8457.

\title{
Los espacios como dispositivo de la construcción de prácticas corporales y coreográficas contemporáneas. A propósito del contact improvisation en el contexto español
}

\author{
María Paz Brozas Polo
}

ANEXOS 
ANEXO 1.-Espacios practicados por la autora como bailarina estudiante o profesora de danza CI.

La Caldera. Centro de Creación de Danza y Artes escénicas (Barcelona 1997); Área. Espacio de danza y creación (Barcelona, 1999); INEF de Castilla y León (1999-2002); Universidad de León (Facultad de Filosofía, Facultad de Educación, FCAFD, Aulario, 2007-2017); Museo de Arte Contemporáneo de Castilla y León (2008, 2009, 2015, 2016, 2017); Centro Coreográfico de León (2000-2003); La Casa de Cultura de Trobajo del Camino (León, 2009); Espacio teatral Asura (Madrid, 2009-2011); Arlequi. Centro de danza y teatro (Bañolas, 2010); C.P. Villanueva de Pría (Asturias, 2011); Espacio de Danza y Meditación Druna (Praga, 2011); Espacio de Arte El Gallo (Salamanca, 2012); La Nómada. Sala de arte y movimiento (Salamanca, 2013, 2014); La Pequeña Nave de Circo de León (2014, 2015); Real Conservatorio Superior de Danza María de Ávila (Madrid, 2013, 2017); Facultad de Motricidade Humana, Universidad Politécnica de Lisboa (2005-2006), Asociación Lunati Contact (Amelia, Italia, 2008); Polideportivo Freiburg Contact Festival (Alemania, 2009-2010); Espacio de investigación en artes escénicas La Luna nell Pozzo (Ostuni, Italia, 2011); Espace Multitude (París, 2012); El cielo de la vera. Lugar de encuentro (Cáceres, 2012); Casina Settarte (Ostuni, Italia, 2012-2016); Universita degli Studi (Roma, 2013); Campamento de Cala Jondal (Ibiza, 2011-2015); Ponderosa Mouvement \& Discovery (Alemania, 2014); Espacio Vías. Centro juvenil municipal (León, 2014-2015); Micadanse (Paris, 2014, 2017); Supercinema. Danza (Tuscania, Italia, 2014); Asociación Sirio (Caudiel, Alicante, 2014); La Casona del Uno (Garganta la Olla, 2015); La Zarza Dojo (Quintana del Castillo, León, 2015); Espacio de arte Gran Angular, (Buenos Aires, 2015); Studio Keller, (Paris, 2016); Toninospace (Barletta, 2016); La fábrica de Chocolate y el Centro Municipal de Danza (Zaragoza, 2016); Casa de Cultura (Donillas, León, 2016); School of Performing Arts (Universidad de Malta, 2016); Centre National de la Danse (Pantin, 2017); IES Villajunco (Santander, 2017). 
ANEXo 2.--Referencias de espacios con práctica de CI en España hasta 2015.

1. Albergue Juvenil de Viznar (Granda). <http://www.proexdra.com/>.

2. Almacabra. Teatrocirco (La Coruña). <http://almacabra.blogspot.com.es/ $>$.

3. Arlequi. Centro de danza y teatro (Banyolas). $<$ http://www.arlequi.de $>$.

4. Anaglifos. Sala de Arte (Barcelona). <http://www.anaglifos.es/>.

5. Annet Wolter. Danza Contemporánea (Almería). <http://anettwolter.com/>.

6. Área. Espacio de danza y creación (Barcelona). <http://www.areadansa.com/>.

7. Asha-kiran. Desarrollo humano, desarrollo social (Madrid). $<$ http://asha-kiran.org.es/espacio/>.

8. Asociación Sirio (Caudiel, Castellón). <http://www.asociacionsirio.com/>.

9. Aula de Artes del Cuerpo, ULE (León). $<$ http://artesdelcuerpo.actividadesculturales.unileon.es/>.

10. Aula de Danza UCO (Córdoba). <https://auladanzauco.wordpress.com/>.

11. Aurea social (Barcelona) Cooperativa Integral Catalana. $<$ http://www.aureasocial.org/es/>.

12. Bacantoh Cia y Asociación Cultural (Barcelona). $<$ http://bacantoh.blogspot.com.es>.

13. Baile en el aire. Encuentro, Naturaleza, Creación (Pitres, Granada). $<$ http://baileenelaire.com/>.

14. Belin Cabrillo. Centro de Danza. $<$ http://www.belincabrillo.onored.com/actividades.htm/>.

15. Bellydance Feeling. Escuela de Danza (Almería). $<$ http://www.cristinasamaniego.com/>.

16. BambúDanza. Centro de arte y movimiento (Madrid). $<$ http://www.bambudanza.com/>.

17. Campamento de Cala Jondal (Ibiza). <http://ibizacontactfestival.com/>.

18. Ca'n Danus. Galería de Arte (Palma). $<$ https://es.foursquare.com/v/can-danus/4f2af653e4b04cc8cf203277>.

19. Carepilates (Madrid). <http://www.carepilates.es/>.

20. Casa de Cultura de Morales del Vino (Zamora).

21. Casa de Cultura de Trobajo del Cerezo (León).

22. Casa Sorábile en (Navarra, entre San Sebastián y Pamplona). $<$ http://www.sorabile.com/>.

23. Casals de Joves Palau Alos (Barcelona) Espacio de encuentro. $<$ http://www.palaualos.cat/>.

24. Casals La Fustería (Cardedeu, Barcelona). <http://www.lafusteria.org/> .

25. Centro Cívico de la Barceloneta (Barcelona). $<$ http://www.bcn.cat/centrecivicbarceloneta/ $>$.

26. Centro de Danza Hélade (Burgos). <http://www.ciudaddeladanza.com/helade/>.

27. Centro de Danza Karen Taft (Madrid). $<$ http://www.karentaft.com/sobreelcentro.php>.

28. Centro Juvenil La Nave (Murcia). $<$ http://www.informajoven.org/juventud/participacion/lanave.asp $>$. 
29. Centro Párraga. Investigación y desarrollo para las artes escénicas (Murcia). $<$ http://www.centroparraga.es/>.

30. Centro Baobab. Comunicación y desarrollo personal (Málaga) $<$ http://centrobaobab.blogspot.com.es/>.

31. Centre Civic Flassarders (Palma). <http://www.flassaders.org $>$.

32. Centre de Recerca de Cultura Contemporánia (CRCC) de Palma.

33. Centro Alma. Psicoterapia (Córdoba). <http://www.centroalma.es/>.

34. Centro cívico Les Planes (Barcelona) $<$ http://www.sjdespi.com/sjd_es/la_ciutat/cultura/equipaments_culturals/>.

35. Centro de Recursos Juveniles de Cartagena (Murcia). $<$ http://juventud.cartagena.es/>.

36. Centro Indira (León). $<$ https://www.facebook.com/pages/Centro-Indira-Yoga-Danza-Fisioterapia/>.

37. Centro juvenil La Fortuna (Leganés, Madrid).

38. Centro La Espalda (Salamanca). <https://plus.google.com/104776170801218782445/>.

39. Centro Social Okupado Autogestionado CSOA El resplandor (Palma de Mallorca).

40. CEP de Alcalá de Guadaíra. $<$ http://www.redes-cepalcala.org/spip/manuelosada/spip.php?article314>.

41. Circo Bajo el Tejado. (Gijón). <http://circobajoeltejado.blogspot.com.es/>.

42. Círculo Pacense. Sociedad cultural y recreativa (Badajoz). $<$ http://circulopacense.com/>.

43. Colegio Dolors Graners (Cardedeu, Barcelona). $<$ http://es.schoolmars.com/colegio-ramon-macip-dolors-granes-cardedeu-26260/>.

44. Colegio Concertado Leonardo da Vinci (Murcia). $<$ https://www.facebook.com/centroleonardodavinci>.

45. Conservatorio de Música y Danza de Palma. $<$ http://www.conservatoridemallorca.com/web2/>.

46. Conservatorio Superior de Danza de Málaga. <http://www.csdanzamalaga.com/> .

47. (Real) Conservatorio Superior de Danza de Madrid María de Ávila. $<$ http://www.csdma.es/>.

48. (Real) Conservatorio Profesional de Danza Mariemma (Madrid). $<$ http://www.rcpdanza.com/>.

49. Conde Duque. Centro Cultural (Madrid). <http://www.condeduquemadrid.es/>.

50. Colegi del Teatri (Barcelona). $<$ http://www.coledeteatredebarcelona.com/cursos.jsp $>$.

51. Corral de Luna (Sevilla). <https://separtedelarte.wordpress.com/acerca-de/localespasaje-mallol/corral-de-luna-estudio-de-artes-plasticas-y-espacio-multidisciplinar/>.

52. Cortijo Los Baños Al-Hamam (Lucainena de las Torres, Almería). $<$ http://www.cortijo-al-hamam.com/>.

53. Cortijo El Saltador. Lucainena de las Torres (Almería). $<$ http://www.elsaltador.com/es/es_cortijo.htm>

54. Cristina Samaniego. Bellydance feeling (Almería). $<$ http://www.cristinasamaniego.com/>

55. CRCC cuartel de Intendencia (Palma de Mallorca). 2009-2012

56. CSOA Sa Foneta (Palma de Mallorca). <https://safoneta.wordpress.com/>.

57. Cuartel de Artillería. Un espacio cultural del Ayto. de Murcia. $<$ http://cuarteldeartilleria.org/>. 
58. Dance4Dance. (Santander). <https://es-es.facebook.com/dance4dancesantander>.

59. Date un respiro. Óriva (Granada). $<$ https://dateunrespiroorgiva.wordpress.com/nosotros/>.

60. D-Espacio. Encuentro creativo social (Oviedo). <http://www.partycipa.com/>.

61. Danzagunea-Arteleku. Centro de arte y cultura contemporáneo (Errentería). $<$ http://dantzagunea.gipuzkoakultura.net/>.

62. Dolcamar. Arte y Entretenimiento. <https://beenaps.com/es/dolcamar-barcelona/>.

63. Dojo Zaragoza. Artes Marciales y Deportes de Contacto.

$<$ http://dojozgz.blogspot.com.es/>.

64. EBCD Eva Bertomeu. Centro de Danza (Valencia). <http://ebcd.es/>.

65. Eduardo Latorre. Complejo deportivo municipal (Alcoy).

$<$ http://www.eduardolatorre.es/>.

66. El Arsenal. Espacio de Creación (Córdoba). $<$ http://elarsenaldechinales.blogspot.com.es/>.

67. El Botanic Spai de Dansa (Valencia). <http://www.botanicespaidedansa.com/>.

68. El Graner. Centro de Creación, Cuerpo y Movimiento (Barcelona). $<$ http://granerbcn.cat/>.

69. El Hervidero. Centro de arte. Sótano de la Galería Espacio Líquido (Gijón). $<$ http://www.arteinformado.com/guia/o/el-hervidero-101023>.

70. El Timbal. Artes escénicas (Barcelona). <http://www.escolateatre.com/>.

71. El Quirófano. Espacio Cultural Independiente (Murcia). <http://elquirofano.net/>.

72. El UP. Sala de Actividades Consciencia Corporal (Barcelona). $<$ http://www.elup.es/>.

73. EnClave. Creación contemporánea (Granada). <http://enclavegranada.wix.com/>.

74. Energy Dance. Escuela de Baile y Agencia de Ocio (Alicante). $<$ http://www.energydance.org/academia-baile-alicante.html>.

75. Entre Arrels. Centro de terapias (Sineu, Mallorca). $<$ http://www.entrearrels.com/centro.html $>$.

76. ENEstudio (Barcelona). <http://enestudiobcn.blogspot.com.es/>.

77. Entre Arrels. Sineu (Mallorca). Centro de terapias naturales y formación cuerpomente. <http://www.entrearrels.com/centro.html>.

78. Escuela de Arte Dramático de Málaga. <http://www.esadmalaga.com/>.

79. Escuela de Arteterapia Hephaisto (Barcelona). $<$ http://www.arteterapiahephaisto.com/eventos $>$.

80. Escuela de Danza Carmen Senra (Madrid). <http://danzacarmensenra.es/>.

81. Escuela de Danza Zinzaló (Manzanares del Real, Madrid). $<$ http://zincalo.blogspot.com.es/>.

82. Escuela Municipal de Música y Danza de San Sebastián (San Sebastián). $<$ http://www.donostia.org/info/musikaeskola/>.

83. Escuela de Arte Dramático de Extremadura (Cáceres). $<$ http://esadextremadura.juntaextremadura.net/>.

84. Escuela de Yoga Prana (Alicante). <http://www.pranaescueladeyoga.com/>.

85. Espacio en Blanco. Danza (Madrid). $<$ https://www.facebook.com/espacioenblanco.madrid/>.

86. Espacio Espiral. Laboratorio escénico y de artes afines (Santander). $<$ http://www.espacioespiral.es/>. 
87. Espacio Vías. Centro juvenil municipal (León). $<$ http://leonocio.es/espacio-vias-leon/>.

88. Espacio ZM. Espacio Cultural (Sevilla). <http://www.salazanfonamovil.com/>.

89. Espacio-R-Danza (Mallorca). <http://foro.cocolilo.com/danza-expresion-corporalyoga/-Espai-R-Danza-Contemporanea.html>.

90. Espacio Temporal (Madrid). <http://madrid.salir.com/espacio_temporal>.

91. Espai Marabal. Artes del cuerpo (Barcelona). <http://www.marabal.org/>.

92. Espai de circ. Asociación valenciana de circo (Valencia). $<$ http://www.espaidecirc.com/>.

93. Espay La Banyera. Danza, Teatro, Música (Barcelona). $<$ http://espailabanyera.blogspot.com.es/>.

94. EMDC Escuela Municipal de Danza de Celrá. <http://escoladedansa.celra.cat/>.

95. Es local. Son Cladera (Mallorca). <https://infoeslocal.wordpress.com/>.

96. Espacio en Blanco (Madrid). $<$ https://www.facebook.com/espacioenblanco.madrid/>.

97. Espacio escénico DT (Madrid). <http://www.dtespacioescenico.com/>.

98. Estudio3. Teatro, cine, danza y desarrollo personal (Madrid). $<$ http://www.estudio3.org/>.

99. Estudio 12 (Zaragoza). <https://www.facebook.com/Estudio12zaragoza/>.

100. Estudio de Mona Belizán (Sa Vileta, Mallorca).

101. Estudio de Danza De Ceglie (Madrid). <http://www.decegliestudio.com/>.

102. Foro Artístico. Asociación Cultural (Murcia). $<$ https://www.facebook.com/foroartistico $>$.

103. Happy Yoga Central (Barcelona). <http://www.happyyoga.com/>.

104. Hotel Sada Marina (La Coruña).

105. IES Castellar (Badajoz). <http://iescastelar.juntaextremadura.net/>.

106. IES de Astorga (León). <http://iesastorga.centros.educa.jcyl.es/>.

107. IES Los Salados (Benavente, Zamora). $<$ http://iesolossalados.centros.educa.jcyl.es/sitio/>.

108. IES Río Duero (Zamora). <http://iesrioduero.centros.educa.jcyl.es/sitio/> .

109. Jazar. Espacio creativo (Pamplona). <http://arkitiriteros.blogspot.com.es/>.

110. Karola Zirko Espazioa (Bilbao). <http://www.karolazirko.net/espacio/>.

111. KUKU Espacio colectivo (Aguilar de Campoo, Palencia). $<$ https://kukuprojekt.wordpress.com/>.

112. INDARGI. Centro de Crecimiento Personal (Pamplona). $<$ http://www.indargi.es/cursos.html $>$.

113. La Casa Amarilla (Madrid). $<$ http://tomasgimeno.wix.com/la-casa-amarilla\#!quienes-somos2/>.

114. La Casa del Agua. (Palencia). <http://escueladeteatroalkimia130.blogspot.com.es/>.

115. La Casa del Búho. Conciencia y grupo (Cádiz). $<$ https://lacasadelbuho.wordpress.com/>.

116. La Casa Invisible. Centro social cultural gestión ciudadana (Málaga). $<$ http://lainvisible.net/>.

117. La Casina del Árbol (Avilés, Asturias).

118. La Casona del Uno (Garganta la Olla, Cáceres). $<$ http://lacasonadeluno.besaba.com/>. 
119. La Chimenea Escénica. (Murcia).

$<$ http://chimeneaescenica.wordpress.com/cursos-regulares/>.

120. La Caldera. Centro de Creación de Danza y Artes escénicas. (Barcelona) $<$ http://www.lacaldera.info/>.

121. La Casa con Alas (León). <http://lacasaconalas.blogspot.com.es/p/danza-contac.html>.

122. La drecera (Barcelona). Espacio libre.

$<$ https://www.facebook.com/ladrecera.guinardo/timeline>.

123. La fàbrica de Chocolate. Espacio artístico (Zaragoza).

$<$ http://madeinzaragoza.es/lafabricadechocolatetuespaciocultural/>.

124. La Excéntrica. Escuela de teatro, clown, impro \& freaks (Madrid).

$<$ http://laexcéntrica.es/>.

125. La Galería espacio abierto (Zaragoza). <http://www.lagaleriadeltango.com/>.

126. La Guajira. Asociación sociocultural. Espacio multifuncional (Almería). $<$ http://laguajiradealmeria.blogspot.com.es/>.

127. La Luz. Centro ecuestre. (Álora, Málaga). <http://ride77.com/>.

128. La pequeña nave. Espacio Escénico de la PVC Circo (León). $<$ http://www.lapvcirco.es/>.

129. La Poderosa. Espacio para la danza y sus contaminantes (Barcelona). $<$ http://www.lapoderosa.es/>.

130. L'animal al'esquena. (Lugar de investigación para la práctica artística basada en el cuerpo) (Celrá, Gerona). <http://www.lanimal.org/>.

131. La Puerta Roja. Pilates \& Danza (Madrid). <http://www.lapuertaroja.net/>.

132. La Nave. Centro de Actividades Artísticas, de Conciencia y Vida (Ibiza). $<$ http://www.lanaveibiza.com/>.

133. La Nave. Creación Interdisciplinar (Madrid). $<$ http://navegandoaladeriva.blogspot.com.es/2008/05>.

134. La Nómada. Sala de arte y movimiento (Salamanca). $<$ http://www.lanomada.es/>.

135. La Pantera Rossa. Centro Social Librería (Zaragoza). $<$ http://www.lapanterarossa.net/>.

136. La petite. Artes escénicas (Granada). <http://salalapetite.blogspot.com.es/>.

137. La Salvia. Salud, yoga... (Málaga). <http://centrolasavia.blogspot.com.es/>.

138. La Semilla Bolonia (Tarifa, Cádiz). <http://www.lasemillabolonia.com/>.

139. La Tabacalera. Centro Social Autogestionado (Madrid). $<$ http://blogs.latabacalera.net/>.

140. La Térmica. Espacio Cultural. Diputación de Málaga. $<$ http://www.latermicamalaga.com/>.

141. La Variable. Espacio de trabajo compartido (Valencia). $<$ https://www.facebook.com/lavariablegranada/>.

142. La Zarza Dojo. Refugio Multidisciplinar (Quintana del Castillo, León). $<$ http://www.lazarzadojo.es/>.

143. Lalita Devi. Escuela de Vida (Cáceres). <http://lalita.net/>.

144. La Bombonera. Espacio de teatro, danza y circo (Granada). $<$ http://escuelalabombonera.blogspot.com.es/>.

145. Los Castaños. Complejo rural y de salud (Cercedilla, Madrid). $<$ https://loscastanoscasarural.wordpress.com/>. 
146. Los pájaros. Ateneo huertano (Murcia). <http://www.lospajaros.org/> .

147. Manicómicos. Artes escénicas (La Coruña). <http://manicomicos.org/>.

148. Muelle3. Danza + Creación (Bilbao). <https://muelle3.wordpress.com/>.

149. MUSAC. Museo de Artes Contemporáneo Castilla y León (León). $<$ http://deacmusac.es/>.

150. PIC Punt d'Interacció de Collserola (Barcelona). $<$ http://www.canmasdeu.net/category/arxiupic/>.

151. Paso a Paso. Escuela de Danza (Almería). <http://danzapasoapaso.com/>.

152. Polideportivo El Cabanyal (Valencia). $<$ http://www.deportevalencia.com/instalaciones/poliesportiu-el-cabanyal/>.

153. Puertas de Castilla. Centro cultural (Murcia). <http://puertasdecastilla.es/>.

154. Re.Colectivo. Un proyecto de revitalización rural (Camás, Asturias). $<$ http://www.recolectivo.net/el-espacio/>.

155. Recrea. Cooperativa de Ocio Educativo (Málaga). <http://www.gruporecrea.es/>.

156. Sa Taronja. Asociación Cultural (Andrax, Mallorca). $<$ http://sataronja-es.blogspot.com.es/>.

157. Sala Maquondo. Bienestar y desarrollo personal (Málaga). $<$ http://www.maqondo.es>.

158. Sala de Arte el Gallo (Salamanca). $<$ http://www.guiadelocio.com/salamanca/arte/salamanca/el-gallo $>$.

159. Sala Danza Mobile (Sevilla). <http://danzamobile.es/>.

160. Sala La Excéntrica. Sala teatral (Madrid). <http://www.laexcentrica.es/>.

161. Sala Saltamontes. Espacio Multidiciplinar (Valencia). $<$ http://saltamontessala.blogspot.com.es/>.

162. Salita "Sin nombre" en el barrio de El Born (Barcelona). $<$ http://movimientoesencial.blogspot.com.es/>.

163. Studio8. Escuela de Teatro (Santa Eulalia, Ibiza). $<$ http://www.studio8ibz.com/home.html>.

164. Terapia Humanista (Málaga). <http://www.terapiahumanista.es/centro>.

165. Tragantdansa. Educación y creación en movimiento (Barcelona). $<$ http://www.tragantdansa.com/>.

166. Taio Dojo (Madrid). <http://www.taio.es/>.

167. Tenshikan Dojo (Sevilla). <http://sevilla.salir.com/tenshikan_dojo_aikido>.

168. Xantala. Espacio de educación libre (Barcelona). <http://www.xantala.es/es/>.

169. USAL. Escuela de Zamora. $<$ http://www.expresiva.org/files/PDF_Esc/Prog_09_ESCUELA_2007.pdf $>$.

170. Yoga Ananda. Ciudatella (Menorca). $<$ https://www.facebook.com/anandamenorca/>.

171. Zaldi Urdina. Escuela de arte, espacio de creatividad (San Sebastián). $<$ http://zaldiurdina.com/category/zaldi-urdina/>.

172. 3Armonías. Disciplinas para el cuerpo, emociones y mente (Oviedo). $<$ http://3armonias.com/>. 